\title{
LA SOBRECONSTITUCIONALIZACIÓN DEL DERECHO DE SEGUROS: EL COMPAÑERO PERMANENTE O CÓNYUGUE DEL MISMO SEXO COMO BENEFICIARIO A TÍTULO LEGAL EN EL SEGURO DE VIDA*
}

\section{THE ON-CONSTITUCIONALIZACIÓN INSURANCE LAW: PERMANENT COMPANION SPOUSE OR SAME-SEX AS A LEGAL TITLE BENEFICIARY IN LIFE INSURANCE}

\author{
Diego Mauricio Manrique Chaves** \\ Fecha de recepción: 30 de junio de 2016 \\ Fecha de Aceptación: 15 de julio de 2016 \\ Disponible en línea: 30 de Julio de 2016
}

\section{Para Citar este articulo/To cite this article}

Manrique Chaves, Diego Mauricio, La sobreconstitucionalización del derecho de seguros: El compañero permanente o cónyuge del mismo sexo como beneficiario a título legal en el seguro de vida, 44 Rev.Ibero-Latinoam.Seguros, 91-139 (2016). http://dx.doi.org/10. 11144/Javeriana.ris44.scds

doi:10.11144/Javeriana. RIS, 44.scds

\footnotetext{
* El presente trabajo es fruto de labores investigativas desarrolladas en el marco de investigaciones interdisciplinares.

** Diego Mauricio Manrique Chaves. Abogado Universidad Nacional de Colombia, cursando Maestría en Derecho Privado Económico de la misma Universidad. Ex funcionario de la Superintendencia Financiera de Colombia en la Delegatura para Aseguradoras e Intermediarios de Seguros. Se desempeña como Investigador en los grupos de investigación, ANI (Arbitraje Nacional e Internacional) profesor Director Magistrado Auxiliar de la Corte Suprema de Justicia Dr. Fredy Andrey Herrera Osorio; Observatorio de Derecho Penal (Nullum crimen sina legem) profesor Director Dr. Omar Huertas, categoría C en Colciencias y Derecho económico y mercado silencioso, profesor Director Dr. Juan Jorge Almonacid. Contacto: dmmanriquec@unal.edu.co
} 


\section{RESUMEN}

El presente artículo da cuenta de la sobreconstitucionalización del derecho, como fenómeno jurídico acrecentado en el derecho privado económico en especial en el derecho de seguros, por cuenta de pronunciamientos jurisprudenciales de la Corte Constitucional, que han limitado libertades económicas, ello con el fin de otorgar insumos para la defensa. Se evidenciarán líneas jurisprudenciales relativas a la limitación de libertades económicas, junto con el análisis de estas decisiones y sus repercusiones. Por último el artículo trae, un ejemplo de constitucionalización del derecho de seguros por cuenta de la designación de beneficiario a título legal de compañeros y conyugues del mismo sexo, en el seguro de vida, con el fin de dimensionar el fenómeno de la constitucionalización en un caso que pese a no estar resuelto del todo, otorga pautas interpretativas claras para desentrañar respuestas jurídicas a esta problemática.

Palabras clave: Constitucionalización del derecho privado; Sobreconstitucionalización; sobreconstitucionazación del derecho de seguros; Corte Constitucional; aseguradoras; seguro de vida; beneficiario a título legal; conyugue del mismo sexo; compañero permanente del mismo sexo; libertades económicas; autonomía de la voluntad privada; derechos fundamentales; cláusulas constitucionales; tiranía constitucional; jurisprudencia constitucional. 


\section{ABSTRACT}

This article reports the On-constitutionalization of law as legal phenomenon increased in the economic private law especially in the insurance law, on behalf of jurisprudential rulings of the Constitutional Court that they have limited economic freedoms, this in order to provide inputs for their defense. They are granted. jurisprudential lines for limiting economic freedoms will become apparent. Finally, the article brings an example of constitutionalization of insurance law, on behalf of the beneficiary designation to legal title colleagues and spouses of the same sex, in life insurance, in order to gauge the phenomenon of constitutionalization in a case that although not entirely resolved, gives interpretive guidelines to unravel clear legal answers to this problem. Plus some additional comments around the agricultural insurance, potential, limits and interdisciplinary research needs are left, to the development of this, which may be an important branch in some years.

Key words: Constitutionalization of Private Law; On-constitutionalising; on-constitucionazación the Insurance Law; Constitutional Court; Insurance; Life Insurance; beneficiary of a legal title; spouse of the same sex permanent partner of the same sex; Economic Freedom; Autonomy of the Will private; Fundamental Rights; Constitutional clauses; constitutional tyranny; constitutional jurisprudence.

\section{SUMARIO}

INTRODUCCIÓN. 1. Las libertades económicas en el ordenamiento jurídico Colombiano, un recuento histórico y normativo. 2. Constitucionalización del derecho privado. 2.1. La sobre-constitucionalización. 2.2 Elementos especiales de la constitucionalización del derecho de seguros 3 . El compañero permanente y el conyugue del mismo sexo, como beneficiarios supletivos del seguro de vida. 3.1. Aborde doctrinal de la problemática: La naturaleza del beneficiario natural en el seguro de vida. 3.2 La mera liberalidad en la designación del beneficiario. 3.3 Asegurador, asegurado, tomador y beneficiario. 3.4 Aborde normativo y constitucional de la problemática: El beneficiario supletivo a título legal. 3.5. Exequibilidad condicionada del artículo 1142 del C.co sobre beneficiarios a título legal. 3.6 Proceso de reclamo del seguro de vida. CONCLUSIONES. BIBLIOGRAFÍA. 


\title{
INTRODUCCIÓN
}

\author{
"Todo poder que se arroga facultad de definir sus propios \\ límites es desbordado, próximo a la tiranía, al despotismo, \\ los excesos y las demasías.".
}

Kant ha sido uno de los precursores más notorios de la libertad y del derecho a que cada persona decida por si misma aspectos relacionados con su vida privada, cuando postuló la mayoría de edad (Moreno Urán. 2008). Sin embargo no es posible concebir el ejercicio de las libertades por fuera del orden social y jurídico ejercido por el Estado, quien mediante teorías contractualitas, a través de dimensiones coactivas, práctica la regulación social y actúa en representación de los intereses colectivos.

Las libertades, en su concepción amplia, sufren limitaciones a diario en las democracias modernas por cuenta de discursos que han permeado los ordenamientos jurídicos, sociales y económicos alrededor de América Latina, sin embargo este discurso cobra especial relevancia en Colombia y se consolidará mucho más por cuenta de los escenarios de posconflicto que se avecinan con la implementación de los acuerdos y políticas estatales de los acuerdos de $\mathrm{paz}^{2}$.Lo que se vive en la práctica, es el nacimiento de una nueva forma de democracia y administración de la justicia a partir de la constitucionalización del derecho. De suerte que el discurso del constitucionalismo, vela por los derechos colectivos, el

1 Corte Suprema de Justicia (2004). Declaración pública Corte Suprema de Justicia de fecha 3 de marzo del 2004. (En línea. (Recuperado el día 18 Julio del 2016, disponible en http:// www.ramajudicial. gov.co/csj_portal/assets/Revista\%20No.\%2018.pdf). Quien procurando defender su autonomía institucional y observando críticamente el comportamiento de la Corte Constitucional La Corte Suprema de Justicia adelanta la confrontación institucional bajo la trivial óptica de una mera lucha entre poderes es. Lo que está en juego no es otra cosa que la independencia y la autonomía judicial $y$, en general, de las ramas del poder público. Ha considerado propicia la oportunidad de expresar su patriótica preocupación y prender las alarmas sobre un peligro más formidable que se traduce en el ejercicio de un poder absoluto en cabeza de la Corte Constitucional, quien proclama, sin reato, su infinito poder, prevalida de ser único guardián de la Constitución y so pretexto de la defensa de Derechos Fundamentales, para someter a todos los demás poderes públicos. Todo poder que se arroga facultad de definir sus propios límites es desbordado, próximo a la tiranía, al despotismo, los excesos y las demasías."

2 Urna de Cristal, 2016. Acuerdos de la Habana. (Recuperado el dia 29 de Agosto del 2016, disponible en http://www.urnadecristal.gov.co/sites/default/files/acuerdo-final-habana.pdf) Por cuenta de los acuerdos firmados en la Habana, relativos a los reforma agraria integral, Participación en política, Narcotráfico y cultivos ilícitos, Sometimiento a la justicia (Subpunto), Acuerdo definitivo sobre víctimas, Implementación, verificación y refrendación. 
interés público en detrimento de las libertades individuales, promotoras del desarrollo, la empresa y el bienestar general y no desestima recursos en defensa de los derechos humanos de primera generación ${ }^{3}$ y en defensa derechos colectivos, con última frecuencia, como materialización del desarrollo de dignidades económicas.

Lo anterior se evidencia en la consolidación de discursos de derechos humanos, mediante enfoques diferenciales, integrales, humanos e interseccionales ${ }^{4}$ que incentivan prácticas legislativas. De igual forma leyes de carácter social, como las agrarias, relativas a restitución de tierras, zonas de reservas campesinas, derechos indígenas, raizales, afrocolombianos y sexuales, para población diversa y carente de protección, permiten dilucidar un marco jurídico cada vez más amplio en protección de los menos favorecidos.

De suerte que, la concepción del estado liberal democrático moderno de a poco se desvirtúa, aquel Estado basado en consideraciones conceptuales como "laissez faire, laissez passer le monde va de lui mé-

3 Ello por cuentade discursos contemporáneos que reafirman los derechos humanos a nivel internacional, y que tienen obligatoriedad para los estados, incluso llegan a formar parte de los bloques de constitutcionalidad de los estados. Entre los tratados internacionales más importantes, que informan el bloque de constitucionalidad, contando con la misma jerarquía de la Constitución política de 1991, se encuentran Acuerdo sobre la asistencia a la niñez. Ley 468 de 1998; Carta de las Naciones Unidas Convencion Americana sobre Derechos Humanos. Ley 16 de 1972; Convencion Interamericana para prevenir sancionar y erradicar la violencia contra la mujer; Convencion Interamericana para prevenir y sancionar la tortura; Convencion Interamericana sobre concension de los derechos politicos a la mujer; Convencion Interamericana sobre derechos civiles de la mujer; Convencion Interamericana sobre restitucion de menores; Convencion Interamericana sobre trafico internacional de menores. Ley 470 de 1998; Convencion sobre la imprescriptibilidad de los crímenes de guerra y los crímenes de lesa humanidad; Convencion sobre la obtencion de alimentos en el extranjero. Ley 471 de 1998; Convencion sobre los derechos del niño; Convenio 169 de la OIT sobre pueblos indigenas y tribales en países independientes; Convenio de Ginebra para aliviar la suerte que corren los heridos, los enfermos y los naufragos de las fuerzas armadas en el mar; Convenio de Ginebra relativo a la protección debida a las personas civiles en tiempo de guerra; Convenio de Ginebra relativo al trato debido a los prisioneros de guerra; Convenio Internacional para la protección de obtenciones vegetales. Ley 243 de 1995; Declaracion de los derechos del retrasado mental; Declaracion de los derechos del niño; Declaracion sobre la protección de todas las personas contra la tortura y otros tratos o penas crueles, inhumanos o degradantes; Declaracion Universal de los Derechos Humanos; Pacto Internacional de derechos civiles y políticos; Pacto Internacional de derechos económicos, sociales y culturales (Corte Constitucional/ tratados, 2016 http://www.corteconstitucional.gov.co/ relatoria/TRATADOS.php)

4 La interseccionalidad se presenta como un discurso en derechos humanos que ha tomado fuerza, por cuenta del cual surgen grupos especiales de discriminados o desfavorecidos, que se encuentran en más de una esfera de discriminación a la vez, y que por tanto merecen especial protección constitucional. Encuentra especial relación con las doctrinas de enfoque diferencial. Algunas providencias constitucionales que desarrollan estos enfoques son los autos de la Corte Constitucional $N^{\circ} 251$ protección de Niños, niñas y adolescentes del 2008; 004 protección a indígenas, 005 protección Afrodescendientes, 006 protección discapacidad y 092 protección mujeres víctimas, todos estos del 2009. 
me» (dejad hacer, dejad pasar, el mundo funciona por sí mismo) ${ }^{5}$ de a poco muere, para dar paso a un Estado de derecho constitucionalizado, que tiene en incertidumbre jurídica las libertades económicas, empresariales, de inversión. Lo que da cuenta de por qué Colombia a nivel internacional, es considerado uno de los países más complicados para hacer negocios y preservar inversiones útiles ${ }^{6}$.

De suerte que los empresarios, reales, del sector financiero, y con un enfoque especial en el desarrollo de este artículo, del sector asegurador, deben conocer lo suficiente esta realidad Estatal, jurídica y empresarial, máxime en escenarios de posconflicto. Es necesario conocer las implicaciones económicas y políticas, del proceso de paz, que en un principio representan nuevas oportunidades de negocio, pero puede representar nuevos escenarios de constitucionalización adversos. Ello supone, no escatimar esfuerzos, por estudiar el marco normativo empresarial discriminado de cada sector, con la suficiente agudeza como para encontrar oportunidades pero también riesgos constitucionales en el ejercicio de las actividades económicas.

De manera que es innegable la tensión permanente entre los alcances de las libertades individuales (manifestada en la autonomía contractual) y las restricciones establecidas por las normas sociales, como también es evidente la postura favorable a esta última, que ha adoptado las Corte Constitucional. Postura que ha sido cuestionable, por su violación a principios básicos de la dogmática jurídica como la seguridad jurídica, la cosa juzgada, la igualdad ante la ley, la no retroactividad de las normas, la protección a las libertades individuales y económicas, la autonomía de la voluntad, la autonomía contractual, creando entonces la "tiranía constitucional" de la que habla la Corte Suprema de Justicia, que de no ser estudiado y prevenido a su profundidad, será una arma de doble filo para el sector empresarial Colombiano.

5 Laissez faire adjudicadas a Pierre Samuel du Pont de Nemours (1739-1817), teórico fisiócrata francés, pero con mayor asiduidad a Jean-Claude Marie Vicent de Gournay (1712-1759)

6 Doing Business. Doing Business 2016, (Revisada el 29 de Agosto del 2016, disponible en http:// www.doingbusiness.org/ /media/GIAWB/Doing\%20Business/Documents/Annual-Reports/English/ DB16-Full-Report.pdf) "data for Colombia The first section presents the Ease of Doing Business rank (out of 189 economies) and the distance to frontier (DTF)measure, overall and by topic. The second section summarizes the key indicators for each topic benchmarked against regional average".

7 María Luisa Rodríguez Peñaranda, Heber Joel Campos Bernal, 2013. , Imperialismo Constitucional. UNIJUS._Este término no dista mucho de otros ya utilizados en la literatura jurídica para definir los poderes omnímodos y omnipresentes de la Corte Constitucional y la constitucionalización del derecho como el utilizado Imperialismo Constitucional, a no ser que representa una preocupación del sector privado y la Constitucionalización del derecho privado, financiero y de seguros. 
Primero, se abordara la libertad en la Constitución Colombiana, desde un punto de vista histórico y dogmático, con el objetivo de dimensionar jurídicamente el fenómeno; segundo, se desarrollará conceptualmente el fenómeno de la constitucionalización del derecho, se evidenciará en la jurisprudencia Colombiana los alcances nefastos de la sobre- constitucionalización del derecho de seguros que en suma representa el límite a la libertad económica, la autonomía contractual y la propia propiedad, por cuenta de los postulados de los derechos colectivos, el interés general y la tiranía de las mayorías; tercero, se evidenciará el caso del otorgamiento de la indemnización al compañero permanente del mismo sexo, en el seguro de vida, con lo cual se pondrá de manifiesto, un problema constitucional que hoy enfrentan las compañías, el Estado, los operadores judiciales y administrativos, y por último, cuarto se expondrán las conclusiones.

\section{LAS LIBERTADES ECONÓMICAS EN EL ORDENAMIENTO JURÍDICO COLOMBIANO, UN RECUENTO HISTÓRICO Y NORMATIVO}

En Colombia el tratamiento a la propiedad privada, se matiza en las sucesivas constituciones de la República, desde la Cundinamarca de 1811. "El Gobierno garantiza a todos sus ciudadanos los sagrados derechos de la religión, propiedad y libertad individual, y la de imprenta". En la Constitución de 1821, "Los derechos del hombre en sociedad son la igualdad y libertad legales, la seguridad y la propiedad", "Ninguno podrá ser privado de la menor porción de su propiedad, ni ésta será aplicada a usos públicos, sin su propio consentimiento, o el del Cuerpo Legislativo".

En la Constitución de 1886, la invulnerabilidad del patrimonio, se extiende a todos los derechos adquiridos con justo título, con límites en el interés púbico, que se verterá en términos de moralidad, salubridad y utilidad. Con lo que se matiza que el derecho inviolable absoluto, pasó a ser derecho que "entraña obligaciones, cuyo uso debe ser igualmente en el interés general" o "derecho subordinado a los intereses de la economía nacional".

La propiedad acompañada de la libertad económica, constituyen principios medulares del origen liberal clásico. Para la economía de mercado, la libertad económica constituye la base de la libertad política 
y es el instrumento mediante el cual cada sujeto se garantiza su propio bienestar. Visión que experimenta modificaciones en el Estado social de derecho, en lo que se ha denominado como la libertad económica en una economía social de mercado. La Corte Constitucional, ha definido la libertad económica, como la facultad que tiene toda persona de realizar actividades de carácter económico, según sus preferencias o habilidades, con miras a crear, mantener o incrementar un patrimonio ${ }^{8}$, sin embargo ha dejado en claro los límites a la propiedad por cuenta del interés social, y detrás de ello discursos de derechos humanos.

\section{CONSTITUCIONALIZACIÓN DEL DERECHO PRIVADO}

Todo sistema jurídico es un sistema jerárquico y dinámico ${ }^{9}$ y es jerárquico en la medida en que los actos jurídicos adquieren validez en razón de su conformidad con otras normas jurídicas superiores que dependen, a su vez, de otras y así sucesivamente, hasta llegar a la norma fundamental, que no tiene justificación jurídica, pero se presupone por todas las normas y todos los actos jurídicos del sistema. En Hart este modelo se traducía en la regla de reconocimiento como la regla de identificación del sistema jurídico. Es asimismo dinámico porque las normas inferiores y los actos jurídicos no pueden ser tan solo derivados de las normas que condicionan su validez, sino que estas proveen únicamente un marco dentro del cual puede encuadrarse válidamente la creación de las normas inferiores, así como la decisión de los actos jurídicos de aplicación.

Como bien lo señala Raúl Gustavo Ferreyra, (Ferreyra, 2015, pag 215) la regla constitucional, en efecto la supremacía de la constitución es el pos-

8 Corte Constitucional, Sentencia C-228/10 LUIS ERNESTO VARGAS SILVA M. P. "Toda persona de realizar actividades de carácter económico, según sus preferencias o habilidades, con miras a crear, mantener o incrementar supatrimonio". Corte Constitucional, Sentencia C-263/11, abril 6 del 2011, RAD: D-8270, JORGE IGNACIO PRETELT CHALJUB, M.P. “Se reconocen dos tipos de libertades económicas: la libertad de empresa y la libre competencia. ... que limita las libertades económicas, la Corte ha indicado que: en primer lugar.... la facultad que tiene toda persona de realizar actividades de carácter económico según sus preferencias o habilidades, con miras a crear; la Carta, la jurisprudencia constitucional ha concluido que las libertades económicas son..... tiene toda persona de realizar actividades de carácter económico, según sus preferencias o habilidades, con miras a crear, mantener o incrementar su patrimonio". Corte Constitucional, Sentencia C-197/12, 14 de marzo 2012, RAD: D-8533, JORGE IGNACIO PRETELT CHALJUB M.P, "la facultad que tiene toda persona de realizar actividades de carácter económico, según sus preferencias o habilidades, con miras a crear, mantener su patrimonio "

9 Kelsen, Hans, Teoría pura do Direito, Comimbra, Aremnio Amado, 1979, pag 269 
tulado sobre el cual se asienta el propio derecho constitucional contemporáneo, oriundo de la experiencia estadounidense. Así, la constitución goza de supremacía jurídica con relación a las demás normas del sistema jurídico, y como consecuencia, ninguna norma o acto jurídico puede subsistir válidamente en el sistema si fuera incompatible con la misma.

Para Germán Bidart Campos (Campos, 2014, 97) sostener que la constitución goza de supremacía puede tener dos sentidos diferentes, primero, saber que la constitución material es la base o fundamento que otorga efectividad y funcionalidad al orden jurídico-político de un Estado o, segundo, que la Constitución en sentido formal, por estar revestida de supra-legalidad y supremacía, impone como deber que todo el mundo jurídico inferior a ella sea congruente y compatible, la prueba de dicho sistema es la jurisdicción constitucional en donde existen mecanismos de control de constitucionalidad.

De igual forma las constituciones contemporáneas establecen reglas de derechos fundamentales, entendidos como lo enseña Noberto Bobbio (Asís Roig, 2010, pag 46), como derechos históricos, ya que surgen a partir de determinado contexto social y cultural de la humanidad, naciendo de forma gradual, modificándose y desapareciendo conforme a las necesidades existentes en las sociedades. A partir de la irradiación constitucional sobre el ordenamiento jurídico, la constitucionalización del derecho es un fenómeno emanado de la interacción de la propia constitución y las demás normas, con lo que la interpretación y aplicación de las normas están regidas por la constitución.

El eje central a partir del siglo XX lo constituye la Carta Magna ${ }^{10}$. Para el surgimiento de una mentalidad constitucionalista se necesitó además del reconocimiento de la fuerza normativa de la constitución, la creación de una jurisdicción constitucional y con el ello una dogmática nueva en cuanto a la interpretación constitucional. De esta forma a partir del siglo XX se comenzó a considerar que la constitución es norma jurídica. En Colombia la constitucionaliación del derecho se extiende a todas las ramas de las ciencias jurídicas desde 1991 con la carta de navegación, la Constitución Política.

10 Konrad - Adenauer - Stiftung, Anuario de derecho constitucional latinoamericano, Edición 2004, pag 113 "Dentro de la fuentes mediatas, la ley fundamental de Boon (constitución de Alemania de 1949) y en especial el surgimiento del Tribunal Constitucional federal en 1951, en segundo lugar, la Constitución Politica italiana de 1947 y la creación de la Corte constitucional de 1947 y en tercer lugar la creación de Corte Constitucional de Portugal 1982, en Cuarto lugar el Tribunal Constitucional Español de 1978". 
Desde el comienzo la Corte se constituyó para algunos autores como Vicente de Jesús Arrieta Flórez (Arrieta Flórez, 2009), en una piedra en el zapato para el sistema financiero, para el ejecutivo y hasta para Magistrados de la Corte Suprema de justicia y del Consejo de Estado. La Corte Constitucional es el órgano de cierre en materia constitucional, fue establecida por el constituyente para velar por la guarda y supremacía constitucional, tiene la potestad de revisar las decisiones de las altas cortes vía tutela. Por vía de tutela la corte ha contribuido a la constitucionalización y humanización del derecho colombiano.

Si en algo se ha caracterizado la Corte Constitucional es de avanzar profusamente en la consagración de derechos constitucionales, en la modernización sobre la interpretación del derecho. En donde el paradigma de interpretación clásico de la centralidad de la Ley a partir de la nueva constitución de 1991, ha comenzado a ser reemplazado por la centralidad de la constitución, es decir se ha pasado de un criterio de legalidad a un criterio de constitucionalidad.

En específico sobre la definición de la constitucionalización del derecho privado utilizaremos la definición utilizada por Juan Jacobo Calderón Villegas (Calderon Villegas, 2007, 117) quien afirma que “consiste en el proceso con ocasión del cual, la Constitución irradia o impregna todo el ordenamiento jurídico impidiendo que el análisis del mismo pueda omitir consideraciones relacionadas con la incidencia de normas constitucionales en su comprensión entendiéndose como la influencia que el derecho constitucional, a través de la aplicación de las disposiciones de la Constitución, pueda llegar a tener en el entendimiento y puesta en marcha de las instituciones del derecho civil y comercial." Es decir el proceso en virtud del cual las cláusulas constitucionales proyectan su eficacia jurídica sobre instituciones clásicas del derecho privado y sobre las normas que las definen y desarrollan, incidiendo en la determinación de su alcance.

Este mismo autor expone que se puede constatar sistemas, entre ellos legislativos y judiciales, mediante los cuales se da paso a la constitucionalización del derecho mercantil, diferenciándose estos, en que el primero desarrolla un modelo de abstracto, por el contrario de sistemas que exponen un predominio de la actividad judicial, con ocasión de los cuales se desarrolla de forma concreta, particular y abstracta. Desde el sistema judicial, este tipo de constitucionalización tendrá lugar con ocasión del ejercicio de funciones jurisdiccionales, independientemente 
del foro al cual se acuda, ya sea la Jurisdicción Ordinaria, Constitucional, Arbitral o incluso aquellas ejercidas por la Superintendencia de Sociedades, de industria y Comercio o Financiera ${ }^{11}$.

El sistema judicial estricto de constitucionalización del derecho mercantil se concreta, para este autor, específicamente cuando a. La autoridad judicial que examina la controversia de derecho privado hace parte de la jurisdicción constitucional, b. el trámite para solucionar la controversia es excepcional y nace de la interposición de una acción de tutela, c. se plantea un problema de derecho privado con matices constitucionales. En estos casos dado que se aduce la violación de un derecho constitucional, la solución deberá ser abordada a la luz de un proceso de argumentación constitucional pese a ser un asunto de derecho privado.

De esta manera, sostiene el autor, que este sistema moviliza toda la infraestructura con la finalidad de resolver una controversia que, prima facie, podría entenderse captada por el ordenamiento comercial y todo el arsenal interpretativo que se ha podido construir a su alrededor. En estos casos de lo que se trata es que desde la perspectiva de los sistemas concretos de solución de disputas del derecho privado, en dado caso que se encuentre la violación de un derecho iusfundamental, la interpre-

11 Con ocasión del artículo 24 del Código General del Proceso, Ley 1564 2012, se activan las facultades jurisdiccionales de la Superintendencia de Industria y Comercio y Financiera. La Superintendencia Financiera de Colombia de acuerdo con lo dispuesto en el numeral $1^{\circ}$ del artículo 325 del Estatuto Orgánico del Sistema Financiero (Decreto 663 de 1993), modificado por las Leyes 510 de 1999 y 795 de 2003 es un organismo de carácter técnico adscrito al Ministerio de Hacienda y Crédito Público, al que le corresponde ejercer funciones en su condición de máxima autoridad de vigilancia y control de las entidades que integran los sistemas financiero, asegurador y previsional del país. Conforme al artículo 121 de la Constitución Política, las autoridades sólo tienen competencia en relación con las materias a su cargo y con sujeción a las funciones a ellas asignadas que, en el caso de esta Superintendencia, se refieren a aquellas señaladas en los artículos 325 y siguientes del citado Estatuto con sus modificaciones y adiciones.En este orden, de conformidad con lo previsto en el artículo 28 del Código de Procedimiento Administrativo y de lo Contencioso Administrativo (CPACA), esta Entidad profiere los conceptos de carácter general y abstracto a que haya lugar con motivo de las consultas que le son formuladas sobre las materias de su competencia o relacionadas con sus atribuciones.

Sobre este particular, en (José Luis Benavides, 2015, Comentarios al Código Contencioso Administrativo y de lo Contencioso Administrativo, Universidad Externado de Colombia, pag 35), se pronuncia de la siguiente manera: "El ejercicio del derecho de petición bajo la modalidad de formulación de consultas a las autoridades conduce a una respuesta llamada concepto, en la cual la respectiva autoridad brinda información relacionada con temas que son de su competencia, o profiere una simple opinión con ocasión de preguntas que deben versar sobre el marco normativo aplicable a la entidad y a sus usuarios, o bien sobre la manera como normalmente se ejercen las competencias de la autoridad" En estos temas, el literal e) del numeral 3 del artículo 326 del Estatuto Orgánico del Sistema Financiero, señala como función de esta Superintendencia la de "Absolver las consultas que se formulen relativas a las instituciones bajo su vigilancia y decidir las solicitudes que presenten los particulares en ejercicio del derecho de petición de información". 
tación constitucional en la comprensión del derecho privado resultará entonces fundamental.

Esta última afirmación, se configura como uno de los aportes significativos para este artículo, en la medida que permite sostener que los operadores judiciales que conozcan de demandas de reclamación de indemnización, en contra de compañías aseguradoras, por parte de beneficiarios supletivos, de una unión permanente del mismo sexo o como suscriptores del contrato de unión solemne, tendrían que abocar por un proceso de argumentación constitucional, pero más importante que ello una interpretación constitucional que incidan en determinar el alcance de las normas comerciales.

Lo anterior fundamentado en que la constitución irradia o impregna todo el ordenamiento, a partir de cláusulas constitucionales que proyectan su eficacia jurídica sobre instituciones clásicas del derecho privado y si este proceso de constitucionalización se desarrolla mediante el llamado Sistema ordinario suave, en el cual una situación concreta conocida como un asunto civil o arbitral que encuentre violación de un derecho iusfundamental, se debe propender por solucionar el asunto, a la luz de un proceso de argumentación constitucional, basado en la interpretación constitucional del derecho privado.

La proyección de la Constitución sobre el sistema económico se evidencia especialmente en el clausulado de la Constitución Económica de 1991. Sus antecedentes se remontan, al germen incipiente de la Constitución de 1886, pero con acrecimiento y decantación sustancial, en el proyecto de la Comisión Tercera de la Asamblea Nacional Constituyente. De tal suerte, que el artículo 333 prevé que la actividad económica y la iniciativa privada son libres dentro de los límites del bien común. Y desarrolla el derecho fundamental a la libertad económica desde el aspecto de la libre competencia, la libertad de empresa y el derecho a la propiedad, como antecedente del liberalismo clásico, reflejado desde la proclamación de los Derechos del Hombre (y mujer) y ciudadano/a 1789, la Constitución de Weirmar en el la República Federal Alemana $1949^{12}$, y como antecedente Latinoamericano la Constitución de Méxi-

12 Tribunal Constitucional Federal, Sentecia Luth Sentencia BVerfGE 7, 198, Sentencia de la Primera Sala, del 15 de enero, 1958. De igual forma ocurre en Alemania, en donde con la expedición de la Ley Fundamental de Bonn en 1949, y a través de la sentencia Ruth que fue el inicio para la consolidación de las retoricas constitucionales. Entre las decisiones judiciales más importantes que han marcado paso para la consolidación discursiva del derecho constitucional en el derecho privado se encuentra la sentencia Luth en la que el Tribunal Constitucional Federal pone de presente la irradiación de los derechos fundamentales en todo el ordenamiento jurídico, incluido el derecho privado o entre particulares. 
co 1917.El régimen económico, comprende dentro de sus actividades el mercado de recursos y financiamiento con lo que se crea un régimen Financiero y Asegurador Colombiano, que a diferencia de la Constitución de 1886, es regulado por mandato constitucional y no sólo legal, con el importante principio constitucional, popular en los Estados Sociales de Derecho contemporáneos de intervencionismo, supervisión, control, y un cada vez más débil planificación de la economía.

En este desarrollo la incidencia de la Corte Constitucional ha sido fundamental en la medida en que ha aplicado los más amplios clausulados constitucionales a realidades prácticas que revisten necesariamente la intervención del interprete máximo. Sin embargo no se encuentra plenamente desarrollada una disciplina jurídica que dé cuenta de la magnitud que representan los fenómenos de constitucionalización del Derecho de seguros, que es solo una arista más de las ya renombradas constitucionalizaciones del Derecho privado, entre ellos el civil, el Mercantil, Comercial, Sociedades, Financiero y ahora aseguraticio.

\subsection{La sobre-constitucionalización}

La sobreconstitucionalización, es un fenómeno consecuente con la atribución de fuerza normativa a la constitución, con la creación de tribunales encargados de proteger la integridad de las normas en las que se plasma, podría decirse un pacto fundamental, un pacto contractual en el cual se depositan derechos, intereses de distintos sectores sociales ${ }^{13}$.

13 En este sentido mediante la sentencia de la Corte Constitucional, T-240 de 1993, JUNIO 23 DE 1993, REF: Expediente T-9665 Magistrado Ponente:Dr. EDUARDO CIFUENTES MUÑOZ reiterada por la sentencia Corte Constitucional T-222 8 de marzo del 2004, Referencia: expediente T-740383, Magistrado Ponente:Dr. EDUARDO MONTEALEGRE NEGRET," respecto de que problemas tienen un poder de captación tal para tener que ser resueltos por la Corte Constitucional. Y por ello no resulta viable considerar constitucionalizada una controversia mercantil, en el sentido de que se encuentra exigida la aplicación directa de la constitución y habilitada para ello la jurisdicción constitucional cuando, 1. Existe una norma de rango inferior, compatible con la Constitución, que resulte más próxima al supuesto de hecho analizado y, como consecuencia de los anterior, 2. Sólo puede predicarse de la Constitución una relevancia genérica que exige de la jurisdicción ordinaria interpretar las normas pertinentes de conformidad con los principios y valores constitucionales. En palabras de la corte "es importante advertir que no es suficiente para des-contitutucionalizar- que denota la ausencia de aplicación directa de la constitución como quiera que la genérica se postula con carácter necesario habida consideración de la obligada interpretación de todo el ordenamiento conforme la Constitución-un asunto encontrar en el ordenamiento una norma de rango no constitucional que de manera directa lo regule y que, por lo tanto, sea la más próxima a la materia controvertida. Deberá primeramente descartarse, como se ha hecho en este caso, la pertinencia de la constitución. Desde luego si la autoridad pública aplica la norma inferior, prescindiendo de interpretarla de conformidad con la Constitución, sus normas, valores y principios, de modo que por ese motivo su decisión los contradiga, puede eventualmente, presentarse por este concepto, una violación directa a 
Con lo que la constitucionalización tiene niveles, con ocasión de los distintos intereses de la sociedad, de la lejanía material de las partes y de la prevalencia de concepciones de Estado.

Es por ello que en especial en el caso Colombiano no es descabellado hablar de constitucionalismo acrecentado tanto así que incluso puede llegar, si es que no lo es ya, a tiránico por cuenta de los límites a las libertades que se dan a los ciudadanos. En Colombia cada vez es mayor el número de textos ordinarios afectados por los textos constitucionales, con lo que se acrecienta el problema de la constitucionalización del derecho y de la activadad privada.

No es extraño ver como ciertas libertades del Estado en este sentido, con la libertad de configuración del legislador y la autonomía de interpretación y aplicación del juez, parecen ser libertades que abanderadas del discurso social y de derechos colectivos, permea la libertad individual. De forma material el papel del estado para garantizar las exigencias de igualdad sustancial llevan a la constitucionalización del derecho privado, sin embargo esta constitucionalización se ve acrecentada por las particularidades Colombianas y que se reflejan en Latinoamérica como son, contexto económico y social deficitario, común nivel de desarrollo bajo, y el impulso de procesos de integración económica, con lo que en este punto son claras las restricciones a la libertad económica y en general a la iniciativa privada por cuenta de la realización e de los derechos sociales y económicos.

\subsection{Elementos especiales de la sobre- constitucionalización del derecho de seguros}

Una primera aproximación a la constitucionalización del derecho de seguros, debe estar orientada a distinguir, que por naturaleza se trata de jurisdicciones distintas. Los asuntos reglados por los privados en ejercicio de sus libertades económicas, contractuales y en concreto de su autonomía de voluntad, esta última como facultad de autodeterminación en relaciones privadas, son ventilados en la jurisdicción

la Carta”. Dado este escenario sólo podrá conocer la jurisdicción constitucional cuando no existan mecanismos ordinarios efectivos para solucionar la cuestión o cuando existiendo tales mecanismos ellos se tornan definitivamente ineficaces para proteger las pretensiones iusfundamentales en juego o el tiempo de espera de su activación puede originar un perjuicio irremediable. En este escenario la constitucionalización de derecho privado desde la jurisdicción constitucional de manera directa puede definir el alcance constitucional de normas mercantiles para resolver una controversia o atraer totalmente la controversia al plano constitucional". 
ordinaria; mientras que los asuntos colectivos, de derechos fundamentales subjetivos ${ }^{14} \mathrm{y}$ de orden público se ventilan en la jurisdicción constitucional.

En principio la propia Corte Constitucional en sent T 240 de 1993, JUNIO 23 DE 1993, REF: Expediente T-9665, M. P. Eduardo Cifuentes Muñoz señaló la importancia del contrato en el proceso de intercambio social, sin embargo también ha señalado que dichos asuntos merecen estar sometidos por la jurisdicción constitucional, y con ello todo un discurso distinto al dogmático civilista, cuando, se presente, como lo reseña la Corte Constitucional, Sentencia T- 1042 de 2001, Septiembre 28 de 2001, Referencia: expediente T-464818, M.P Manuel José Cepeda E, "existencia de una clara relación asimétrica de poder entre los particulares, que de entrada descarta, limita o elimina la autonomía de la persona y justifica una intervención estatal para evitar el envilecimiento ${ }^{15}$ "

Sin embargo, la línea entre ambas jurisdicciones en principio independientes, no se vislumbra con claridad cuando la Corte Constitucional, por cuenta del discurso de irradiación Constitucional, reafirma la oponibilidad de los derechos fundamentales en relaciones de naturaleza contractual. En este punto es relevante citar el estudio del profesor de la Universidad de los Andes Juan Jacobo Calderón Villegas, realizado en el $2013^{16}$, quien luego de analizar el influjo de los filosofía constitucional y el pensamiento propio civilista, aduce proposiciones acerca de la constitucionalización del derecho privado que giran entorno a (i), las entidades financieras tiene el derecho a elegir el tipo y el alcance de las relaciones contractuales en las que pretenden participar, (ii) en ningún evento puede una entidad financiera abstenerse de celebrar un contrato que se articule con el desarrollo de las actividades propias de su objeto social, (iii) necesidad de armonizar el principio de la autonomía de la voluntad con la naturaleza de interés público de las actividades financieras (iv) necesidad de argumentar justificación negativa y razonable a fin de negarse a presar servicios propios de su objeto, so pena de violar derechos fundamentales.

14 Manuel Fernando Quinche, Derecho constitucional Colombiano, TEMIS, 2015, Bogotá, Colombia pag 81

15 Corte Constitucional, Sentencia T- 1042 de 2001, Septiembre 28 de 2001, Referencia: expediente T-464818, M.P Manuel José Cepeda E

16 Calderón Villegas, Juan Jacobo. La constitucionalizarían del derecho comercial: algunas de las huellas trazadas por la jurisprudencia de la Corte Constitucional en Colombia, Universidad del Rosario, 2008. 
Las anteriores proposiciones, sintetizan las soluciones otorgadas a los conflictos generados entre el derecho privado y el derecho constitucional, en especial en cuanto a los nuevos límites de la autonomía de voluntad desde la perspectiva de los derechos humanos y el interés público. De la misma manea resulta necesario interiorizar el clausulado constitucional, encargado del influjo de la constitucionalización del derecho privado, "cláusula general de igualdad (art 13), a la cláusula general de libertad (art 14), o la cláusula general de libertad (art 16), a la libertad de empresa (art 333), a la libre competencia económica (art. 333), al deber de respeto a la personalidad jurídica (art 14), a la obligación de actuar conforme al deber de solidaridad (art. 95), a la exigencia de respetar el principio de la buena fe (art. 83) $)^{17}$ "

Circunstancias estas que reflejan la asertividad de la afirmación de Eugenio Llama Pombo 2009 acerca de la necesidad del civilista de "mantener su mirada permanentemente atenta a la Constitución, pues el conocimiento y estudio de la misma es punto de partida necesario en el análisis de toda la materia civil. Incluso, se llega a reclamar la elaboración de un estudio general del denominado "derecho civil constitucional" 18 .

Pero a estos problemas sería oportuno agregar los problemas morales y políticos que se presentan relacionados directamente con la postura mediante la cual el juez constitucional desarrolla el derecho en un país moralmente conservador y poco progresista, en temas como las parejas del mismo sexo y sus derechos.

Con lo que las principales, por solo nombrar algunas, líneas de limitación a las libertades individuales que de cierto modo son particulares en el contexto colombiano tienen que ver con la protección del derecho al trabajo y la garantía de la libertad contractual en la T-982 del 2001' por la cual se restringió la libertad de contratación por cuenta de un interés individual de religión, al obligar a contratar a una persona que por motivos personales no podía trabajar los sábados, luego en la T-1180 $2002^{20}$, se obligó a una aseguradora a contratar una póliza de seguros

17 Ibid, pag 39

18 Citado de Ibid, Eugenio Llamas Pombo, Orientaciones sobre el concepto el método del derecho civil, Bogotá Universidad Javeriana, 2009, pág 119

19 Sentencia de la Corte Constitucional T 982-2001, el 13 de Septiembre de 2001, Referencia: expediente T-459129, Dr. MANUEL JOSÉ CEPEDA ESPINOSA M.P

20 Corte Constitucional, Sentencia T-1180-2002, Fecha 2 de diciembre de 2002, Referencia: expediente T-1.997.283, MP: Dr. HUMBERTO ANTONIO SIERRA PORTO. Dentro de los escenarios de 
con un grupo de discapacitados, pese a ser un contrato consentido para la ruina y para la ocurrencia del siniestro, con lo que se limitó la libertad contractual y se llegó incluso al punto de sortear el riesgo casi inminente, en el patrimonio de la aseguradora, con lo que no solo se viola la libertad misma de decidir con quién contrato sino que además se viola la propiedad por cuenta de tener que soportar intereses particulares como los del grupo de discapacitados, pero que adquieren relevancia constitucional por cuenta de la protección del estado a estos grupos de personas.

La sentencia. T- 1165 de 2001 es una de las decisiones más polémicas en cuanto a lo que denominaríamos en este caso en especial la sobre-constitucionalización del derecho de seguros, la Corte Constitucional adoptó la decisión de obligar a una aseguradora privada a celebrar un contrato de seguro de vida requerido para amparar el riesgo de muerte de dos personas que padecían de VIH y que lo requerían para acceder a un crédito hipotecario ${ }^{21}$. Luego de ello en la T-517 de $2006^{22}$ y en la T 416 de $2007^{23}$ determino la constitucionalidad de que una

constitucionalizarían del derecho mercantil y en especial de la intromisión de la jurisdicción constitucional en los contratos de seguros, damos cuenta de una larga y elaborada lista de pronunciamientos de la alta corporación constitucional, que ha delimitado la libertad contractual dentro de este tipo de contratos. Dentro de los principales antecedentes se encuentra la sentencia de la Corte Constitucional T 1165 de 2001, fecha 6 de noviembre del 2001, Referencia: expediente T-500.674, MP Dr. ALFREDO BELTRÁN SIERRA, caso en el que se discutió si resultaba constitucionalmente legítimo a la luz del derecho a la igualdad que una compañía aseguradora se negara a celebrar un contrato de seguro vida con un tomador que padecía el síndrome de inmunodeficiencia adquirida. En la T1118 2002, la Sala Tercera de Revisión, evaluó si la decisión negativa de una aseguradora para cotizar el valor de un seguro de accidentes personales a favor de un grupo de discapacitados se oponía al derecho fundamental a la igualdad. En la Sentencia de la Corte Constitucional T 763 del 2005, fecha 9 de diciembre del 2002, Referencia: expediente T-527962, Magistrado Ponente:Dr. MANUEL JOSE CEPEDA ESPINOSA, le correspondió a la Corte determinar si resultaba constitucionalmente admisible, a la luz a la igualdad, que una entidad bancaria negara a un pastor cristiano la activación de una tarjeta débito aduciendo, para el efecto, que ello no era posible dado que la actividad desempeñada por el solicitante no se encontraba en el marco de las políticas de crédito de tal entidad bancaria.

21 Advirtió la Corte: “ De aceptar esta Sala, que la aseguradora acusada puede dejar de suscribir un seguro de vida, bajo un argumento de que la persona que lo solicita padece de virus de inmunodeficiencia humana, sería como aceptar toda forma de discriminación, desconociendo los preceptos constitucionales y las normas contenidas en el derecho internacional, como quiera que si se admite este tipo de exclusiones, muy seguramente, ene l futuro tendría que admitirse que quien es portador de VIH, va a ser excluido de todo tipo de negocio, inclusive se puede llegar a decir que quien es portador de VIH, va a ser excluido de todo tipo de negocio, inclusive se puede llegar a decir que quien es portador del virus no puede trabar, asistir a un centro educativo, tener un contrato de salud, o emplear un medio de transporte" Juan Jacobo Calderón Villegas, La constitucionalización del derecho privado, la verdadera historia del impacto constitucional en Colombia, Universidad de los Andes, Bogotá- Colombia, 2013 pag 63

22 Sentencia de la Corte Constitucional T-517 del 2006, fecha 7 de diciembre del 2006, Referencia: T-1308125, Magistrado Ponente: Dr. MARCO GERARDO MONROY CABRA

23 Sentencia de la Corte Constitucional T-416 de 2007, fecha 24 de mayo del 2007, Referencia: expediente T-1534164, Magistrado Ponente: Dr. ALVARO TAFUR GALVIS 
aseguradora se abstuviese de expedir una póliza judicial advirtiendo su facultad, reconocida en el artículo 1056 del Código de Comercio, de elegir los riesgos.

En estas últimas decisiones merece la pena recordar el comentario del profesor Calderon Villegas ${ }^{24}$, quien recuerda la interpretación más doctrinaria del artículo 1056 del Código de Comercio brindada por el maestro Efren Ossa, totalmente contraria a la "ciertamente original" del artículo 1056 del Código de Comercio que establece la Corte resumida en que la libertad de las aseguradoras se refiere, fundamentalmente, a limitar el alcance de los riesgos que asume y no, genéricamente, a abstenerse de contratar.

En sentencias como T-433 de $1992^{25}$, SU- 157 de $1999^{26}$ y SU- 167 de $1999^{27}$, la Corte establecería que las entidades bancarias prestan un interés público (y luego las aseguradoras mediante sentencia C-432 de $2010^{28}$ ) que limitan sus facultades para restringirse de celebrar relaciones contractuales, excepto si se presenta de manera objetiva una razón de justificación.

En la sentencia T 375 de $1997^{29}$ se obligó de igual forma a contratar a un empresario que distribuía parafina con una persona que dependía económicamente de esta empresa, por cuenta de esta regla el estado obligó a contratar con alguien, violando las garantías básicas de liberad, sin prever que esta obligatoriedad por cuenta de derechos particulares protegidos por el interés común podría llevar al absurdo de contrar aun así no se pague, u obligarse a lo imposible con un consumidor que tendría en su domino, por cuenta del derecho adjudicado, prerrogativas excesivas con el empresario.

Para finalizar, se presentará una descripción somera de un problema de constitucionalización, aún no resuelto por la corte Constitucional,

\section{Ibid, pag 133}

25 Sentencia de la Corte Constitucional, T-433de 1992, fecha 24 junio 1992, Magistrado ponente DR. SIMON RODRIGUEZ RODRIGUEZ

26 Sentencia de la Corte Constitucional SU-157 de 1999, fecha 10 de marzo de 1999,r eferencia: Expedientes T-153.327 y T-152.413 (acumulados), Magistrado Ponente: Dr. ALEJANDRO MARTINEZ CABALLERO

27 Sentencia de la Corte Constitucional, SU-167 de 1999, fecha 17 de marzo de 1999, Referencia: Expediente T-176.083, Magistrado Ponente: Dr. ALEJANDRO MARTINEZ CABALLERO

28 Sentencia de la Corte Constitucional C-432 de 2010, fecha 2 junio 2010, Referencia: expediente D-7946, Magistrado Ponente: Dr. HUMBERTO ANTONIO SIERRA PORTO

29 Sentencia de la Corte Constitucional T-435 de 1997, Referencia: Expediente T-130126, Magistrado Ponente: Dr. EDUARDO CIFUENTES MUÑOZ 
pero que refleja todas las zonas grises de constitucionalización sin explorar con especial énfasis a los costes en que tiene que incurrir las aseguradoras en sus estudios de siniestralidad y sus efectos contables.

\section{EL COMPAÑERO PERMANENTE DEL MISMO SEXO Y EL CONYUGUE DEL MISMO SEXO, COMO BENEFICIARIOS SUPLETIVOS DEL SEGURO DE VIDA}

El presente apartado responde a la pregunta de sí ¿tienen las Aseguradoras la obligación de hacer efectiva o de reconocer la póliza de un seguro de vida a parejas del mismo sexo?. En un marco del derecho financiero globalizado y sus interconexiones con la álgida constitucionalización del Derecho, no es pasiva la discusión de la constitucionalización del Derecho de Seguros. Se recoge el debate entre las relaciones contractuales del asegurador y el asegurado, este último desde sus múltiples integraciones, reconstruyendo sus relaciones en un contrato de Seguro de Vida en el que se gestan relaciones conflictivas al momento de hacer exigible el contrato, en especial cuando se trata de un compañero permanente del mismo sexo, que no ha sido designado como beneficiario en el seguro y reclama su derecho a título legal de ser reconocido como beneficiario supletivo a partir de las consagraciones legales y jurisprudenciales. Pero en un derecho furtivo, por demás incierto, los sujetos financieros que interpretan sus relaciones a la luz del derecho de seguros, abocan interpretaciones finalistas pero de sus propios intereses y no de la finalidad del Orden Normativo Colombiano, con lo que es extraño encontrar objeciones, y resistencias a interpretaciones Constitucionales modernas en lo que se convierte en un debate de exegesis en la interpretación de las normas, como una ventana para el escape de la aplicación del derecho constitucional desde un enfoque del derecho de Seguros. Lo que en principio podría parecer un debate superado, por el contrario solo es la punta del aisberg de múltiples relaciones financieras abocadas por la aplicación de derechos fundamentales. Por lo que nos remitiremos a abordar la problemática de quién debe ser considerado como beneficiario supletivo cuando la designación se torna ineficaz o no se hace, abordando la problemática, primero desde un punto de vista normativo, segundo desde un punto de vista constitucional y con este una profundización en el método de interpretación de las normas de seguros desde un enfoque constitucional. 


\subsection{Aborde doctrinal de la problemática: La naturaleza del beneficiario natural en el seguro de vida}

Vale la pena mencionar que el riesgo es el suceso incierto, que no depende exclusivamente de la voluntad del tomador del asegurado o del beneficiario y cuya realización da origen a la obligación del asegurador. Pese a que se afirme que los hechos ciertos y los físicamente imposibles no constituyen riesgos, de manera que los riesgos tienen su nicho de nacimiento entre el lindero de la imposibilidad y la certeza, es conocida que la excepción a esta regla de la naturaleza asegurable de los riesgos , es el riesgo de la muerte, dado que la muerte, hecho cierto, inevitable sí constituye riesgo por ser incierto en el cuándo y de ahí entonces la posibilidad jurídica del seguro ordinario de vida llamado a cubrirlo cualquiera que sea el momento de su realización, que puede sobrevenir en cualquier momento futuro incierto (López Blanco, 2009).

En este sentido luego de determinar que la naturaleza asegurable del riesgo de la muerte, pese a ser cierto, se encuentra en la incertidumbre de su acaecimiento, rescatamos la exposición del profesor Luca Buttaroque que recoge el profesor Ossa, entorno al principio de indemnización en el seguro de vida frente al riesgo de muerte, quien en su ponencia presentada en el Congreso Internacional de Derecho de Seguros titulada "Moerni orientamenti sul concetto giuridico di assicurazione nella dottrina italiana" afirma que con el Bambling Act de 1774, se subordina la validez del seguro sobre la vida de un tercero a la existencia de un interés asegurable y termina por afirmar que el daño resarcible es el que sufre el beneficiario o el que reciben los herederos del asegurado(Ossa Efren, 1985).

En su ponencia este autor no hace más que dar un empuje vigoroso a la teoría jurídica mediante la cual se busca bajo un denominador común, el principio de la indemnización en el seguro de vida, entrelazando las ramas de seguros de daños y seguros de personas. Ello en la medida que el seguro de vida tradicionalmente había sido concebido, como un seguro prestacional de servicios ${ }^{30}$ y no uno indemnizatorio,

30 J.M Piniés- R. Tornil, aRIEL 1973, Manual práctico del seguro sobre la vida, Paris- Francia. "El seguro de vida tiene más de 20 siglos de existencia, la práctica romana de afrontar en común, mediante la distribución del riesgo, las necesidades patrimoniales originadas por la muerte de una persona: el pago de deudas y derechos de sucesión, en el imperio romano existían unas asociaciones de gentes humildes denominadas collegia tenuiorum, que tenian por objeto abonar a los derecho-habientes de la muerte, pertenecientes a la asociación, una cantidad para sufragar los gastos de enterramiento y funerales, a cambio de unas modestas cuitas de entrada y mensual cotizadas por los socios. 
característico de los seguros de daños. Con lo que el autor propone una evolución doctrinaria que bifurcaría de la doctrina tradicional italiana, que concuerda con la Colombiana, al asignar sólo para los seguros de daños el principio de indemnización, que no atribuye carácter indemnizatorio a los seguros de personas, sean estos de accidentes o de vida.

Para esta teoría, la vida no puede considerarse sólo como un atributo de la personalidad humana, un atributo cuya pérdida alcanza solo a la persona fallecida, tal ha sido la equivocada creencia de la doctrina prestacional. Por el contrario el autor cree que la vida es un bien que hace parte del patrimonio individual o por lo menos hay que aceptar que el bien cubierto en el seguro de vida es la ganancia que el asegurado se proponía realizar si hubiese conservado la vida.

La acogida de esta teoría se evidencia en la caracterización del seguro de vida que realiza el profesor Efrén Ossa G., quien afirma que el suscriptor propiamente no concibe el daño, o por lo menos no lo convive en su naturaleza jurídica, este suscriptor busca principalmente y es lo que busca este género de relaciones, proteger a su cónyuge y a sus hijos menores, proteger a los suyos contra las eventuales necesidades a que puedan verse abocados con ocasión de la ocurrencia del siniestro. Necesidades que pueden ser de diverso orden. Y busca secundariamente ya para el caso de que la muerte no sea prematura, formar un capital por medio del ahorro. Con lo que en este punto vale la pena recordar que a medida de que en un seguro de vida corre su vigencia es cada vez menos seguro y cada vez más ahorro. Y que con una u otra función, el suscriptor puede cumplir el mismo objetivo, es decir la protección de los suyos o su protección misma.

Con ello se concluye entonces, que la concepción actual del seguro de vida, es aquella mediante la cual el suscriptor del seguro tiene como móvil determinante del contrato, la indemnización del daño eventual que con su muerte ha de menoscabar su patrimonio, pese a que desde el punto de vista técnico este principio no sea propio de esta clase de seguros. De esta forma lo ha entendido la jurisprudencia de la Corte Suprema de Justicia en el $2005^{31}$ y en el $2007^{32}$. En este sentido, aunque en el Derecho comparado es bastante discutido el concepto de interés

31 Corte Suprema de Justicia, Ref: exp. 05001-3103-001-2006-00038-01, fecha 25 de mayo 2012, Magistrada Ponente RUTH MARINA DÍAZ RUEDA.

32 Corte Suprema de Justicia, Ref.exp Expediente 0500131030021999 00359, fecha 06 Julio de 2007, MP: CARLOS IGNACIO JARAMILLO JARAMILLO 
- estricto- asegurable en los seguros sobre la vida, habida cuenta que si en éste "es imposible aplicar el concepto técnico de indemnización, es evidente que no cabe hablar de un interés, cuyo valor sirva de medida para la reparación de un daño que es imposible concretar".

Pero los efectos doctrinales más importantes de esta concepción del seguro de vida, desbordan en afirmar que el seguro de vida tiene un móvil determinante circundante con el principio de la indemnización y llegan a evaluar en cabeza de quién se radica el daño y qué patrimonio se beneficia con derecho a la indemnización.

El doctrinante responde afirmando que el daño radica, con el derecho a la indemnización, en cabeza de los causahabientes. El patrimonio completo, incluidos la vida y la capacidad de trabajo y de renta, no tienen por qué sufrir quebranto con la muerte y, por lo tanto, deben pasar intacto a los herederos, ello dado que el seguro es precisamente el sustitutivo económico de bienes que, como la vida y la capacidad de trabajo, perecen necesariamente con la muerte, luego dado que el daño lastima el patrimonio de los herederos, en estos se incorpora el derecho a la indemnización, que deberá ejercerse como derecho propio y no jure hereditario.

\subsection{La mera liberalidad en la designación del beneficiario}

Lo anterior evidencia, que por lo menos desde el punto de vista doctrinal, la concepción de los beneficiarios naturales del seguro de vida recae en quienes son los llamados a sufrir las consecuencias patrimoniales por el quebranto con la muerte, quienes no son más que los causahabientes del tomador del seguro de vida, lo que guarda concordancia con el artículo 1142 de beneficiarios supletivos en caso de no designación o designación ineficaz. Sin embargo en el desarrollo práctico y comercial, del seguro de vida individual esta afirmación no es tan pacífica y presenta matices que difieren en cuanto a la determinación del beneficiario del seguro. Y es que la llamada libertad de estipulación determina que tratándose de seguros de personas el beneficiario podrá ser designado por el tomador a su arbitrio, el artículo 1141 del mismo ordenamiento señala que "será beneficiario a título gratuito aquel cuya designación tiene por causa la mera liberalidad del tomador. En los demás casos, el beneficiario será a título oneroso. En defecto de estipu- 
lación en contrario, se presumirá que el beneficiario ha sido designado a titulo gratuito".

De manera que la designación del beneficiario a título gratuito, conforme el tenor literal de la preceptiva citada, no exige más que la voluntad libre del tomador. No se requiere, la norma no lo contempla, que el beneficiario designado sea o deba tener algún grado de consanguinidad o afinidad con el tomador-asegurado del seguro de vida. Con lo que el beneficiario se determina como la persona designada por la mera liberalidad por el tomador en la póliza para recibir el valor asegurado.

En conclusión, pese a que el beneficiario natural del seguro de vida, son los causahabientes por ser quienes soportan de manera directa el daño y quienes se encuentran entonces legitimados para recibir un resarcimiento indemnizatorio, en realidad la libertad de estipulación contenida en el artículo 1141 del C.Co, con la que la mera liberalidad del tomador es la Ley para las partes, surge como característica definitoria de la identificación del beneficiario en el contrato de seguro vida individual. De suerte que la máxima doctrinaria de quien es el beneficiario natural, queda relegada a una norma supletiva de voluntad contenida en el artículo 1142 del C.co, que cubre el defecto o ineficacia de la designación hecha en ejercicio de la liberalidad del asegurado cuando no se hace uso de esta libertad y en defecto no se estipula a nadie como beneficiario.

En virtud de lo anterior, se ha constatado un insumo importante a la hora de abordar el problema de investigación de este artículo, al avizorar la relevancia que la doctrina en materia de seguros le ha otorgado a los causahabientes como sujetos pasivos del daño ocasionado con la muerte y de suyo su legitimidad como sujetos indemnizables.

Es importante en este punto no olvidar la lectura integral de la Ley cuando la designación del beneficiario no se rige por la reglas de la mera liberalidad o cuando rigiéndose por ellas esta se torna ineficaz, dando paso a la aplicación de las normas supletivas de la voluntad el mencionado artículo 1142 y su interpretación integral con el artículo 1137 y por estipulación por referencia realizada de ésta última norma a las reglas de sucesión del artículo 411 del Código Civil. Normas que regulan la sucesión particular del contrato de seguro de vida y que aplican las concepciones de la teoría de la indemnización impulsada por el profesor Luca Buttaroque y la designación de beneficiarios a partir de los lazos de consanguineidad u afinidad. Esta interpretación integral 
será abordada al momento de dar respuesta al problema jurídico planteado en este artículo.

\subsection{Asegurador, asegurado, tomador y beneficiario}

En la relación jurídica que se constituye con ocasión del contrato de seguro, se distinguen tradicionalmente como partes: al asegurador y al asegurado. El asegurador es la persona jurídica que asume los riesgos, es decir a quien son trasladados los riesgos de un tercero, el asegurado, por su parte es el titular del interés asegurable, aquel cuyo patrimonio resulta afectado con la realización del riesgo y quien cumplida la condición, es decir ocurrido el siniestro, adquiere el derecho a la indemnización (Jaramillo, 2009).

En cuanto al asegurado, la situación perfecta se da cuando las condiciones de asegurado y tomador se confunden en la misma persona, en caso contrario se tendrán que distinguir el tomador del asegurado y en caso de quien cobre la indemnización del perjuicio sea distinto de ellos, se deberá distinguir también del beneficiario quien actúa como tercero al no intervenir en la formación del contrato (Ossa, 1985).

El tomador, será entonces, quien hace el traslado de los riesgos, obrando por cuenta propia o ajena, es él quien está llamado a responder por las obligaciones derivadas del contrato bien a interés propio o ajeno, si el tomador obra por cuenta propia confluye en éste la calidad de asegurado, pero sí obra por cuenta ajena, el tomador y asegurado serán dos personas distintas.

Pero para el caso que nos ocupa, en una póliza de seguro de vida las partes tienen una distinción particular. Por regla general el asegurado, es la persona misma sobre cuya vida, integridad corporal, capacidad laboral o salud se celebra el contrato de seguro. En la mayoría de los casos esta persona coincide con el tomador, tal ocurre en el seguro sobre la propia vida. Lo cierto es que el asegurado no puede definirse como en los seguros de daños como el titular del interés asegurable, porque este suele ser el tomador, la persona que, sobre su propia vida o sobre la vida de un tercero y en todo caso por cuenta propia contrata el seguro.

El asegurado es entonces la persona sobre cuya vida se hace el seguro, la que está llamada a padecer eventualmente los riesgos asegurados, la muerte, la desmembración, la incapacidad física o mental que, a su vez, generan o pueden generar el detrimento patrimonial de la persona 
interesada en la traslación de este asegurador y que salvo el seguro para el caso de muerte es la misma persona asegurada.

De igual manera es recurrente la intervención de beneficiarios en el seguro de vida, quienes a pesar de intervenir en la formación del contrato, han de percibir el valor del seguro, en caso de siniestro, ajustado naturalmente con arreglo a sus condiciones y límites. Del beneficiario no existe una definición expresa en el Título $\mathrm{V}$ del Libro Cuarto de Código de Comercio, pero sí es objeto de mención en algunas de sus disposiciones.

En este punto el Maestro Efren Ossa, siguiendo a Luca Buttaroque afirma que en cuanto a la naturaleza del beneficiario, debe existir un fundamento razonable basado en las relaciones entre las partes, bien sea pecuniarias, de consanguineidad o de afinidad, que explique la expectativa del beneficio o de las ventajas de la continuación de vida del asegurado. De lo contrario el contrato sería un puro juego de azar en el que el tomador del seguro está directamente interesado en el pronto fallecimiento del asegurado. Y estas pólizas se encaminarían a crear un deseo de que el evento se produzca.

Incluso, el Maestro Efrén Ossa toma la batuta de realizar una interpretación doctrinaria del artículo 1137 C.co de interés asegurable, en todo caso congruente con el sentido del orden normativo a la luz de la interpretación del maestro, en este caso nos encontramos con que el interés asegurable en el seguro sobre la propia vida, se halla circunscrita a la de un eventual alimentante. Con esta fórmula no solo se permite dar contenido económico al interés asegurable, sino enmarcar la relación de parentesco como sustento legal de dicho interés. De manera que cuando el art.1137 (ord 2) del Código de Comercio preceptúa que toda persona tiene interés asegurable en la vida de las personas a quienes legalmente puede reclamar alimentos, está significando dos cosas:

1. Por una parte que solo las personas enumeradas en el artículo 411 del Código Civil o en otras disposiciones legales tienen, como alimentarios, interés asegurable en la vida de sus eventuales alimentantes, así cualquiera de los conyugues tiene interés asegurable en la vida del otro, los descendientes legítimos en la de sus ascendientes y estos en la de aquellos. Es decir cualquiera de estas personas tiene interés asegurable en la vida del otro. Lo que significa que el cónyuge o compañero o compañera permanente tiene interés asegurable 
en la vida del otro de forma recíproca, el alimentario en la vida de su alimentante y el alimentante en la vida de su alimentario.

2. Basta la mera eventualidad de la prestación alimentaria a cargo del tercero sobre cuya vida se celebra el seguro, para fines de la designación del beneficiario sustituto en los casos en que la designación se hace a título legal.

Con lo que en conclusión, desde el punto de vista doctrinal, se ha dado cuenta del sentido de los artículos 1142, 1137 del C.co y 411 del C.C, junto con el espíritu de las normas, que tienden por entender el móvil determinante del seguro de vida, la indemnización a quienes sufren el daño y que pese a que la mera liberalidad sea la regla general en el tema, en su defecto el régimen exceptuado de la norma coloca de presente los vínculos de consanguineidad, el interés asegurable reciproco enmarcado en las obligación del alimentante a sus alimentarios. De manera que no es nuevo el debate del beneficiario a título supletivo y su justificación en relaciones de consanguineidad, pero sirve de insumo para acentuar que independientemente del tipo de familia, las obligaciones en relaciones de pareja son justificantes del beneficiario natural de un seguro de vida, cuando el siniestro de la muerte acaece y produce un daño resarcible con la indemnización que proporciona el seguro de vida.

\subsection{Aborde normativo y constitucional de la problemática: E1 beneficiario supletivo a título legal}

El derecho a la indemnización del beneficiario es una mera expectativa que está condicionada a la muerte del asegurado, de manera que cuando acaece el siniestro de la muerte, el tomador de la indemnización o prestación asegurada está llamado a realizar la reclamación a la aseguradora. El beneficiario, se determina como la persona designada, en uso de la mera liberalidad del Artículo 1141 C.Co, en la póliza para recibir el valor asegurado en este evento, sin embargo en los casos en que el beneficiario no ha sido designado, este es el caso en beneficiario no es designado ni a título gratuito ni oneroso o su designación torna ineficaz o simplemente no se realiza, entra a suplir la voluntad del tomador por defecto, las reglas consagradas en el artículo 1142 del C.co, como 
norma supletiva de la voluntad, que debe interpretarse en su lectura integral con los Artículos 1137 del C.Co y 411 del C.C.

El artículo 1142 C.co señala que cuando no se designe beneficiario, o la designación se haga ineficaz o quede sin efecto por cualquier causa, tendrán la calidad de tales el cónyuge del asegurado, en la mitad del seguro, y los herederos de éste en la otra mitad ${ }^{33}$, entendiendo a los conyugues también como compañeros permanentes a la luz de la exequibilidad condicionada de la norma que realizó la Corte Constitucional.

La justificación de este precepto, se encuentra en que tanto el conyugue como los hijos, tienen interés asegurable sobre la muerte de su alimentante a la luz del artículo 1137 del C.co ${ }^{34}$ de manera que por referencia se debe acudir al artículo 411 del C.C, que dicta las reglas sobre los sujetos pasivos y activos de la obligación de alimentos, que determina que se deben alimentos a los cónyuges, siempre que se entienda a los conyugues como compañeros permanentes por una unión marital de hecho, a la luz de la exequibilidad condicionada de la norma que efectuó la Corte Constitucional ${ }^{35}$.

33 Artículo 1142 designación de beneficiario, cuando no se designe beneficiario o la designación se haga ineficaz o quede sin efecto o por cualquier causa, tendrán la calidad de tales el cónyuge del asegurado, en la mitad del seguro y los herederos de éste en la otra mitad. Igual regla se aplicará en el evento de que se designe genéricamente como beneficiarios a los herederos del asegurado. Corte Constitucional, Sentencia C-844, fecha 28 de octubre de 2010, Expediente D-8130 Sala Plena. M.P. María Victoria Calle Correa. Spa. La Corte Constitucional declarará exequible la expresión «cónyuge» empleada en el artículo 1142 del Código de Comercio, en el entendido de que dicha expresión cobija por igual al compañero o compañera permanente.

34 Art. 1137._Interés asegurable. Toda persona tiene interés asegurable:

10) En su propia vida;

2o) En la de las personas a quienes legalmente pueda reclamar alimentos, y

3o) En la de aquellas cuya muerte o incapacidad pueden aparejarle un perjuicio económico, aunque éste no sea susceptible de una evaluación cierta.

En los seguros individuales sobre la vida de un tercero, se requiere el consentimiento escrito del asegurado, con indicación del valor del seguro y del nombre del beneficiario. Los menores adultos darán su consentimiento personalmente y no por conducto de sus representantes legales.

En defecto del interés o del consentimiento requerido al tenor de los incisos que anteceden, o en caso de suscripción sobre la vida de un incapaz absoluto, el contrato no producirá efecto alguno y el asegurador estará obligado a restituir las primas percibidas. Sólo podrá retener el importe de sus gastos, si ha actuado de buena fe.

35 ARTICULO 411. . Se deben alimentos:

1o) Al cónyuge. Corte Constitucional - Numeral 1o. declarado EXEQUIBLE por la Corte Constitucional mediante Sentencia C-1033-02 de 27 de noviembre de 2002, Magistrado Ponente Dr. Jaime Córdoba Triviño; "siempre y cuando se entienda que esta disposición es aplicable a los compañeros permanentes que forman una unión marital de hecho". - Numeral 1o. declarado EXEQUIBLE por la Corte Constitucional mediante Sentencia C-174-96 del 29 de abril de 1996. Magistrado Ponente Dr.Jorge Arango Mejía.

2o) A los descendientes legítimos.

3o) A los ascendientes legítimos.

4o) A cargo del cónyuge culpable, al cónyuge divorciado o separado de cuerpo sin su culpa. 
De manera que en ejercicio de la revisión de constitucionalidad de las normas del Código Civil y Código de comercio, se ha establecido la equivalencia sustancial entre conyugues y compañeros permanentes. $\mathrm{Y}$ en cuanto al alcance de una unión permanente del mismo sexo, la Corte Constitucional ha preceptuado que los compañeros permanentes deben entenderse también como los del mismo sexo a la luz, de la exequibilidad condicionada de la Ley 54 de $1900^{36}$.

En conclusión, a partir de una debida interpretación integracional del orden normativo entendiendo inescindiblemente que la exequibilidad de sus normas está sujeta a la interpretación legitima que la Corte Constitucional realice, se torna relativamente sencillo llegar a una respuesta jurídica a la problemática planteada, en los términos del artículo 1142 del C.co, que determina que los beneficiarios supletivos a falta de designación o designación ineficaz, son los conyugues e hijos, entendiendo aquellos también como compañeros permanentes y en el entendido que los compañeros permanentes también son aquellos que se encuentre en unión marital del mismo sexo.

Luego, no existiría problema alguno en otorgar la indemnización del seguro de vida a un compañero permanente del mismo sexo que solicite el beneficio. Sin embargo en la práctica esta simple interpretación normativa, no ha sido planteada ni por el legítimo interprete de las normas, la Corte Constitucional, existiendo sólo un antecedente jurisprudencial en donde se abordó la problemática superficialmente pero sin pronunciamiento de fondo del asunto por no encontrar la Corte los requisitos procesales agotados ${ }^{37}$,ni tampoco por operadores judiciales

5o) A los hijos naturales, su posteridad legítima y a los nietos naturales. - Numeral modificado por el artículo 31 de la Ley 75 de 1968

6o) A los Ascendientes Naturales. - Numeral modificado por el artículo 31 de la Ley 75 de 1968

7o) A los hijos adoptivos.

8o) A los padres adoptantes.

9o) A los hermanos legítimos.

10) Al que hizo una donación cuantiosa si no hubiere sido rescindida o revocada. La acción del donante se dirigirá contra el donatario. No se deben alimentos a las personas aquí designadas en los casos en que una ley se los niegue.

36 LEY 54 DE 1990 (diciembre 28) NOTA: Esta ley tiene aplicación retrospectiva de acuerdo a los establecido por el Fallo 261 de 2011 de la Corte Suprema de Justicia. NOTA: Esta ley tal como fue modificada por la Ley 979 de 2005, fue declarada EXEQUIBLE por la Corte Constitucional, mediante Sentencia C-075 de 2007, en el entendido que el régimen de protección en ella contenido se aplica también a las parejas homosexuales. por la cual se definen las uniones maritales de hecho y régimen patrimonial entre compañeros permanentes.

37 Corte Constitucional Sentencia T-506/15, expediente T-4.849.334, fecha 10 de agosto del 2015, MP: GLORIA STELLA ORTIZ DELGADO, pese a no pronunciarse de fondo por no cumplir la tutela con los requisitos legales de inmediatez y daño irreparable, la Corte de nuevo a reiterado la asimilación del compañero permanente con el cónyuge. 
que se hayan tomado la batuta en el asunto, ni autoridades administrativas que den directrices de manera general o abstracta $^{38}$ y por el contrario, son innumerables los casos en los cuales las aseguradoras se han negado a reconocerle el estatus jurídico de beneficiario supletivo a título legal a compañeros permanentes del mismo sexo, o en su defecto interponen u obstaculizan su consecución con regímenes probatorios cercanos a tarifas legales impuestos por las propias aseguradoras que terminan por agotarse con la prescripción de acciones de las acciones tendientes a lograr la reclamación, con cierta complicidad de operadores jurídicos exegetas, para los cuales la constitucionalizacion del derecho aun es un hito.

En conclusión en los casos en que no ha existido designación expresa del beneficiario, la designación se hará a título legal de acuerdo con las reglas de los artículos 1137, 1142 del Código de Comercio y las del artículo 411 del Código Civil. La designación del beneficiario a titulo legal se dará a favor del cónyuge y herederos en igual porción (1142 C.Co), (que abarca también al compañero o compañera permanente Sentencia C-844 del 28 de octubre de 2010 y exequibilidad condicionada de la Ley 54 de 1900 en el entendido que el régimen de protección en ella contenido se aplica también a las parejas homosexuales por la cual

38 La Superintendencia Financiera de Colombia de acuerdo con lo dispuesto en el numeral $1^{\circ}$ del artículo 325 del Estatuto Orgánico del Sistema Financiero (Decreto 663 de 1993), modificado por las Leyes 510 de 1999 y 795 de 2003 es un organismo de carácter técnico adscrito al Ministerio de Hacienda y Crédito Público, al que le corresponde ejercer funciones en su condición de máxima autoridad de vigilancia y control de las entidades que integran los sistemas financiero, asegurador y previsional del país.

Conforme al artículo 121 de la Constitución Política, las autoridades sólo tienen competencia en relación con las materias a su cargo y con sujeción a las funciones a ellas asignadas que, en el caso la Superintendencia, se refieren a aquellas señaladas en los artículos 325 y siguientes del citado Estatuto con sus modificaciones y adiciones.

En este orden, de conformidad con lo previsto en el artículo 28 del Código de Procedimiento Administrativo y de lo Contencioso Administrativo (CPACA), esta Entidad profiere los conceptos de carácter general y abstracto a que haya lugar con motivo de las consultas que le son formuladas sobre las materias de su competencia o relacionadas con sus atribuciones.

Sobre este particular, en los comentarios al Código Contencioso Administrativo y de lo Contencioso Administrativo, Editor José Luis Benavides, Universidad Externado de Colombia, se pronuncia de la siguiente manera: "El ejercicio del derecho de petición bajo la modalidad de formulación de consultas a las autoridades conduce a una respuesta llamada concepto, en la cual la respectiva autoridad brinda información relacionada con temas que son de su competencia, o profiere una simple opinión con ocasión de preguntas que deben versar sobre el marco normativo aplicable a la entidad y a sus usuarios, o bien sobre la manera como normalmente se ejercen las competencias de la autoridad".

En estos temas, el literal e) del numeral 3 del artículo 326 del Estatuto Orgánico del Sistema Financiero, señala como función de esta Superintendencia la de "Absolver las consultas que se formulen relativas a las instituciones bajo su vigilancia y decidir las solicitudes que presenten los particulares en ejercicio del derecho de petición de información". En todo caso funciones de carácter genera y abstracto. 
se definen las uniones maritales de hecho y régimen patrimonial entre compañeros permanentes.), en el entendido de que el objeto del contrato de seguro de vida, es decir el interés asegurable, recae en un tercero asegurado o beneficiario que es el titular de la prestación asegurada(sin importar si ha sido designado o no), una vez ocurrido el siniestro de muerte, pues en el riesgo de muerte, sería absurdo pensar en una prestación para el difunto. Dado que, cuando el beneficiario es a título legal, su legitimidad en reclamar la prestación se da a la luz de existir un fundamento razonable basado en las relaciones entre las partes, de consanguineidad o de afinidad siendo cónyuges o herederos (1137 C.Co).

Como observo en el acápite de aborde doctrinal, el sustento legal de dichas relaciones, se da en el marco de la obligación alimentaria (411 C.c) en el entendido que tienen, como alimentarios, interés asegurable en la vida de sus eventuales alimentantes, así, como sus alimentarios tienen interés asegurable en la vida de sus alimentantes, con lo que cualquiera de los conyugues tiene interés asegurable en la vida del otro (siempre y cuando se entienda que esta disposición es aplicable a los compañeros permanentes que forman una unión marital de hecho, Sentencia C-1033-02 de 27 de noviembre de 2002, exequibilidad del artículo 411 C.c). Con lo que el compañero o compañera permanente es titular a los mismos derechos que el cónyuge a ser designado como beneficiario supletivo a título legal, al existir una relación de afinidad, justificada en la obligación alimentaria que en últimas define el interés asegurable entre el tomador y el beneficiario.

\subsection{Exequibilidad condicionada del artículo 1142 del C.co sobre beneficiarios a título legal}

La Corte Constitucional en Sentencia C-844 del 28 de octubre de 2010 declaró exequible la expresión "cónyuge” empleada en el artículo 1142 del Código de Comercio, en el entendido de que dicha expresión cobija por igual al compañero o compañera permanente.

En el caso del artículo 1142 demandado, se trata de una disposición orientada a garantizar la protección al patrimonio familiar señalando un mecanismo para los contratos de seguros de personas siempre sea posible precisar quién o quiénes de los miembros de la familia del tomador

39 Corte Constitucional en Sentencia C-844 del 28 de octubre de 2010Sala Plena, M.P. María Victoria Calle Correa. Expediente D-8130 
son los beneficiarios, cuando éste no lo haya hecho expresamente o los haya designado de manera genérica. En esa medida, la protección del patrimonio familiar es un fin legítimo e imperioso a la luz de lo que establece el artículo 42 Superior.

En cuanto al medio escogido por el legislador, el artículo 1142 demandado precisa que en ausencia de una manifestación expresa, tienen derecho a ser considerados como beneficiarios supletivos exclusivamente los hijos y el cónyuge del tomador. Observa la Corte que: si bien es un medio adecuado señalar expresamente quiénes serían los beneficiarios supletivos, no resulta acorde con la Constitución excluir a ciertos beneficiarios que a la luz de lo que establecen los artículos 13 y 42 de la Carta tendrían derecho a ser considerados como beneficiarios supletivos en condiciones de igualdad con el cónyuge, como es el caso de la compañera o compañero permanente.

La disposición contenida en el artículo 1142 del Código de Comercio, expedido en el año 1971, devino parcialmente inconstitucional cuando entró en vigor la Carta, el 7 de julio de 1991, al infringir el derecho a la igualdad de la familia surgida de un matrimonio válidamente celebrado y la originada en vínculos naturales (uniones de hecho). En esa medida, la expresión demandada, vulnera los mandatos constitucionales consagrados en los artículos 13 y 42 del estatuto superior, al establecer que sólo el cónyuge como miembro de la familia originada en el matrimonio puede ser considerado como beneficiario supletivo del seguro, cuando el tomador y causante no lo hizo expresamente, o la designación se torne ineficaz.

Desde una perspectiva constitucional no existe una justificación objetiva y razonable para otorgarle un trato distinto al cónyuge para considerarlo beneficiario supletivo, mientras que el compañero (a) se le excluye de tal posibilidad. No obstante, declarar inconstitucional la expresión cónyuge empleada en el artículo 1142 del Código de Comercio por comportar una discriminación en contra de la compañera o compañero permanente, dejaría sin sentido la norma $y$, además, privaría al cónyuge del derecho en ellas reconocido. En esa medida, la Corte Constitucional declarará exequible la expresión "cónyuge" empleada en el artículo 1142 del Código de Comercio, en el entendido de que dicha expresión cobija por igual al compañero o compañera permanente. 
Es pertinente rescatar la evolución jurisprudencial de la Corte Constitucional en relación la equivalencia sustancial entre el matrimonio y la unión marital de hecho. En sentencias de la Corte Constitucional como Sentencia T.582 del 27 de julio de $2010^{40}$, la Corte ha reconocido que desde múltiples perspectivas el matrimonio y la unión marital son dos opciones vitales igualmente protegidas por la constitución, pero distinguibles en razón de su conformación y efectos jurídicos.

Pese las diferencias entre las dos instituciones, con las cuentan los ciudadanos para conformar una familia, existe una equivalencia sustancial entre el matrimonio y la unión marital de hecho: las dos instituciones dan origen a una familia y, desde este punto de vista, merecen igual protección constitucional. Ha señalado la corte que no puede el legislador expedir normas que consagren un trato diferenciado en cuanto a los derechos y deberes de quienes ostentan la condición de cónyuge o de compañero permanente, como tampoco entre los hijos habidos en matrimonio o fuera de él.

La corte ha declarado inexequibles normas que regulan regímenes prestacionales especiales aplicados de forma desigual a compañeros permanentes y conyugues a las fuerzas armadas o al personal civil del ministerio de Defensa Nacional, cuando consagran un trato discriminatorio entre el cónyuge y el compañero o compañera permanente. Así en la sentencia C-410 de $1996^{41}$, la corte señaló que el artículo 81 del Decreto Ley 1214 de 1990 era inconstitucional por consagrar un trato discriminatorio al reconocer el derecho a acceder a los servicios de asistencia médica, quirúrgica, exclusivamente al cónyuge e hijos menores de 21 años, desconociendo el derecho que de conformidad con el artículo 42 de la Constitución, le asiste al compañero o compañera permanente del afiliado.

En materia de seguridad social en pensiones, en la Sentencia C-1126 de 2004, ${ }^{42}$ la Corte encontró que los artículos 34 del Decreto 611 de 1977 y 49 del Decreto 2701 de 1988, eran contrarios al derecho a la igualdad y a la protección constitucional de la familia, por excluir al

40 Corte Constitucional como Sentencia T.582 del 27 de julio de 2010, Expediente T-2601994. Sala Quinta de Revisión. M. P. Jorge Iván Palacio Palacio

41 Sentencia de la Corte Constitucional C-410 de 1996, fecha 4 de Septiembre de 1996, Referencia: Expedientes D-1203, D-1204, D-1205, D-1206, D-1212, D-1213, D-1214 y D-1218 (acumulados), Magistrado Ponente:Dr. HERNANDO HERRERA VERGARA

42 Sentencia de la Corte Constitucional C-1126 de 2004, fecha 9 de Noviembre de 2004, Ref. Expe D-5259, M.P. Manuel José Cepeda Espinosa. 
compañero o a la compañera permanentes del derecho a la pensión de sobrevivientes, y en consecuencia declaró exequible de manera condicionada la expresión cónyuge, en el entendido de que dichas normas comprendían también al compañero o compañera permanente, a partir del 7 de julio de 1991.

Adicionalmente, la Corte Constitucional también se ha referido a la constitucionalidad de las normas que regulan las sociedades conyugal y patrimonial, y ha resaltado que dichas disposiciones expresan el interés del legislador en garantizar la existencia, al lado de los bienes comunes, de bienes propios de los cónyuges o compañeros permanentes ${ }^{43}$. Así por ejemplo, en la Sentencia C-014 de 1998, ${ }^{44}$ la Corte recordó que la Ley 54 de $1990^{45}$ no consagraba ningún requisito económico para la

43 En la Sentencia de la Corte Constitucional T-494 de 1992, Ref: EXPEDIENTE 1909, M.P. Ciro Angarita Barón, la Corte precisó que la aportación a una sociedad de hecho como la que se derivaba de la unión de hecho podía ser también de industria, y que como tal debía apreciarse el trabajo doméstico. En este sentido expresó que "el desconocimiento del trabajo doméstico de la peticionaria involucrada en la amenaza del despojo, sin debido proceso, del inmueble en que ella habita hoy, adquirido y mejorado progresivamente durante la unión de hecho y como fruto del esfuerzo conjunto de los concubinos, viola abiertamente los derechos constitucionales de igualdad, debido proceso y no discriminación en contra de la mujer, consagrados, respectivamente, en los artículos 13, 29 y 43 de la Carta vigente".

44 Corte Constitucional Sentencia C-014 de 1998, fecha 4 de febrero 1998, Referencia: Expedientes D1735 y D-1740, acumulados, Magistrado Ponente:Dr. EDUARDO CIFUENTES MUÑOZ. En dicha sentencia, la Corte examinó si (1) las personas impedidas legalmente para contraer matrimonio podían conformar una unión de hecho, si sus respectivas sociedades conyugales habían sido disueltas y liquidadas, y (2) si el mayor valor que durante la unión producen los bienes de propiedad personal de uno de los compañeros permanentes ingresaba a la sociedad patrimonial. En dicha oportunidad, la Corte resolvió: "Primero.- Declarar EXEQUIBLE, únicamente en relación con el cargo formulado por el actor, la expresión "e impedimento legal para contraer matrimonio por parte de uno o ambos compañeros permanentes, siempre y cuando las sociedad o sociedades conyugales anteriores hayan sido disueltas y liquidadas por lo menos un año antes de la fecha en que se inició la unión marital de hecho", contenida en el literal b) del artículo $2^{\circ}$ de la Ley 54 de 1990. Segundo.- Declarar EXEQUIBLE, únicamente en relación con el cargo formulado por el actor, la expresión "o mayor valor que produzcan estos bienes durante la unión marital de hecho", contenida en el parágrafo del artículo $3^{\circ}$ de la Ley 54 de 1990. Ello bajo el entendido de que la valorización que experimentan los bienes propios de los convivientes, por causa de la corrección monetaria, no forma parte de la sociedad patrimonial."

45 Artículo $2^{\circ}$. Modificado por la Ley 979 de 2005, artículo $1^{\circ}$. Se presume sociedad patrimonial entre compañeros permanentes y hay lugar a declararla judicialmente en cualquiera de los siguientes casos: || a) Cuando exista unión marital de hecho durante un lapso no inferior a dos años, entre un hombre y una mujer sin impedimento legal para contraer matrimonio; || b) Cuando exista una unión marital de hecho por un lapso no inferior a dos años e impedimento legal para contraer matrimonio por parte de uno o de ambos compañeros permanentes, siempre y cuando la sociedad o sociedades conyugales anteriores hayan sido disueltas y liquidadas por lo menos un año antes de la fecha en que se inició la unión marital de hecho. $\|$ Los compañeros permanentes que se encuentren en alguno de los casos anteriores podrán declarar la existencia de la sociedad patrimonial acudiendo a los siguientes medios: || 1. Por mutuo consentimiento declarado mediante escritura pública ante Notario donde dé fe de la existencia de dicha sociedad y acrediten la unión marital de hecho y los demás presupuestos que se prevén en los literales a) y b) del presente artículo. \| 2. Por manifestación expresa mediante 
declaración judicial de la existencia de una sociedad patrimonial y por ello era suficiente que se comprobara "la existencia de una unión de hecho durante un término no inferior a dos años, con la aclaración de que en los casos en que uno o ambos convivientes tengan impedimentos legales para contraer matrimonio, deben haber disuelto y liquidado sus sociedades conyugales anteriores con una anticipación no menor de un año."

Corte Constitucional ha reconocido que la unión marital de hecho, regulada por la Ley 54 de 1990, debe ser protegida por el Estado. Así, en la sentencia C-098 de 199646, el Tribunal examinó una demanda contra dicha ley y señaló que este tipo de uniones corresponden a una de las formas legítimas de constituir familia, la que se crea no sólo en virtud del matrimonio. De esta manera, la unión libre de hombre y mujer, aunque no tengan entre sí vínculos de sangre ni contractuales formales, debe ser objeto de protección del Estado y de la sociedad, pues ella da origen a la institución familia

Por ejemplo, en la sentencia C-985 de $2005^{47}$, la Corte conoció nuevamente de una demanda contra la Ley 54 de 1990 y concluyó que en la unión marital de hecho, existe un contrato que nace del acuerdo de voluntades. De esta manera, esta declaración de voluntad pertenece al ámbito de la autonomía de la persona cuyo fin primordial se concreta, principalmente, en la posibilidad de elegir. Se trata de una decisión de una pareja para vivir juntos y constituir así una familia, por lo que, en manera alguna se trata de una unión mercantil o patrimonial o de otra índole.

En sentencia C-238 de $2012^{48}$, señaló con precisión que habida cuenta del fundamento constitucional que tiene la familia originada en la unión marital de hecho, es evidente que la ausencia de un soporte textual que expresamente prevea la vocación hereditaria del compañero o compañera permanente que sobrevive al causante, constituye una omisión de carácter relativo, configurada en razón de la entrada en

acta suscrita en un centro de conciliación legalmente reconocido demostrando la existencia de los requisitos previstos en los literales a) y b) de este artículo.

46 Sentencia de la Corte Constitucional C-098 de 1996, 7 de Marzo de 1996, Ref.: Demanda No D-911, Magistrado Ponente: Dr. EDUARDO CIFUENTES MUÑOZ

47 Sentencia de la Corte Constitucional C-985 del 2005, fecha 26 de septiembre de 2005, Referencia: expediente D-5737, MP: Dr. ALFREDO BELTRÁN SIERRA

48 Sentencia de la Corte Constitucional C-238 de 2012, fecha, Referencia expediente D-8662, MP: GABRIEL EDUARDO MENDOZA MARTELO 
vigencia de la Carta de 1991, con lo cual reconoció la existencia de este tipo de familia.

Así, en el ámbito patrimonial, la Corte estimó que los derechos de esta índole deben ser reconocidos a los compañeros permanentes, quienes requieren una protección similar a la que, en el caso de los cónyuges, brinda la sociedad conyugal. De este modo, al reconocer el derecho a suceder, en los respectivos órdenes, solo a quien en vida haya estado unido con el causante en virtud del vínculo matrimonial, se priva de esa concreta medida

La Corte Constitucional ha venido haciendo de la legitimidad patrimonial de las uniones maritales de hecho, también de manera reciente ha desarrollado varias reglas jurisprudenciales que extienden dicha protección a parejas del mismo sexo. Así, en la sentencia C-075 de $2007^{49}$ la Corte señaló con precisión, al conocer una demanda contra la Ley 54 de 1990, que la ausencia de protección en el ámbito patrimonial para la pareja homosexual, resultaba lesiva de la dignidad de la persona humana, y a partir de lo que previamente se había reconocido a favor de los integrantes de las uniones maritales de hecho y que ese reconocimiento favorable a las parejas homosexuales ha llevado a que se proteja su unión de hecho y a que se le tenga por familia originada en un vínculo natural, e igualmente fundada en la voluntad responsable de conformarla, sin que para tal efecto haya sido requisito indispensable la expresa mención constitucional de esta clase de unión de hecho o se haya erigido en impedimento la falta de tal señalamiento explícito.

Pero el desarrollo más importante en cuanto al reconocimiento constitucional de los derechos de las parejas del mismo sexo se encuentra en la Sentencia C-577 del $2011^{50}$, que consagra de una vez por todos los desarrollos constitucionales en el concepto de familia. En esta sentencia la corte busca establecer una institución contractual que responda a las necesidades de protección de las parejas del mismo sexo, a las que les falta un mecanismo que torne factible el reconocimiento formal y solemne de su unión y que contribuya a asignarle deberes y derechos recíprocos a los miembros de la pareja así como su efectivo cumplimiento. En esta sentencia, se afirma que el artículo 42 de la cons-

49 Sentencia de la Corte Constitucional C-075 del 2007, fecha 7 de febrero 2007, referencia expediente D-6362, MP: Dr. RODRIGO ESCOBAR GIL

50 Sentencia de la Corte Constitucional C-577 del 2011, fecha 12 de enero del 2011, referencia Expedientes acumulados D-8367 y D-8376, MP: GABRIEL EDUARDO MENDOZA MARTELO 
titución política no está en contra de los derechos de las parejas del mismo sexo y tampoco impide que se cree una figura jurídica contractual que solemnice la relación surgida de la expresión libre de la voluntad de conformar una familia con mayores compromisos que la originada en la simple unión de hecho.

Pero la sentencia deja en claro que dentro de las formas que se puede utilizar para hacer valer los derechos de las personas homosexuales existe la posibilidad de optar entre la unión de hecho y la formalización de su relación a partir de una vinculación jurídica específica. En lo único que se diferenciaría la unión marital de hecho de unión solemne entre parejas del mismo sexo, sería en que la solemnidad le da una categoría correspondiente a un vínculo jurídico y para efectos probatorios no habría necesidad de allegar pruebas de convivencia para probar el vínculo, como en la unión marital de hecho, sino que sería suficiente con aportar el documento protocolizado por notaria para probar el vínculo.

Quiere decir lo anterior que para lograr que el derecho al libre desarrollo de la personalidad les sea respetado a los homosexuales y que en el ámbito de las regulaciones sobre la familia se supere el déficit de protección al que están sometidos, hace falta en el ordenamiento una institución contractual, distinta de la unión de hecho, que les permitiera optar entre una constitución de su familia con un grado mayor de formalización y de consecuente protección y la posibilidad de constituirla como una unión de hecho que ya les está reconocida.

Es decir la unión marital de hecho es una figura con ocasión de la cual se crean vínculos jurídicos, similares a los de un matrimonio y en razón a conformar una familia, a partir de la prueba de convivencia superior de una pareja de dos años ${ }^{51}$, mientras que la unión solemne de parejas del mismo sexo, es una institución con ocasión de la cual se crean vínculos jurídicos similares al matrimonio y en razón a conformar una familia, pero a partir de una institución contractual con fundamento en un vínculo jurídico contractual ${ }^{52}$.

La diferencia resultante entre el matrimonio y la unión solemne radicaría únicamente en la literalidad de las expresiones que se utilizan

51 Sin significar esto que dentro de las parejas del mismo sexo no existan obligaciones desde el momento de la convivencia Sentencia c075 2007, Corte Constitucional

52 Si alguna prohibición se advierte, no se relaciona con la existencia de tal figura o institución contractual, sino con los límites que se deben observar al instituirla, límites que, principalmente, tienen que ver con la no afectación del reconocimiento y la expresa protección que el artículo 42 contiene respecto del matrimonio como institución que, por mandato constitucional, da origen al vínculo jurídico constitutivo de la familia conformada por la pareja heterosexual. 
para denotar una familia, el matrimonio como el contrato en virtud del cual se conforma una familia heterosexual mientras que la unión solemne sería el contrato en virtud del cual se conforma un matrimonio homosexual. Pese a las múltiples críticas de la comunidad académica que consideran esta figura como un paño de agua fría, que en el fondo reconoce derechos pero nunca como un matrimonio, sino como una figura similar de menor jerarquía, como la unión solemne y que incluso no otorgaría los mismos derechos que un matrimonio en el contexto de las relaciones internacionales, en las cuales en ciertos países el permiso de residencia se otorga al cónyuge, por lo cual quedarían excluidas las parejas del mismo sexo por no poder casarse.

Concuerdo en que ha sido una decisión con vacíos, la pareja en un matrimonio se denomina cónyuge, la pareja en una unión marital de hecho, se denomina compañero permanente y el compañero en una unión solemnizada de parejas del mismo sexo, ¿cómo se denomina?, si de cierto es que es una figura que comporta los mismos derechos que el matrimonio, no debería entonces también denominarse cónyuge, o cónyuge de unión solemne? A la postre la sentencia SU 214/16 ${ }^{53}$ que determino la procedencia del matrimonio de pareas del mismo sexo, resolvió estas dudas dando el mismo tratamiento a los conyugues y a los compañeros permanentes del mismo sexo, de suerte que con la consagración del matrimonio entre parejas del mismo sexo, se determina la suerte de conyugue.

Y ahora para complejizar aún más la situación, si el artículo 1142C. co no hace mención a las parejas del mismo sexo, podría acaso entenderse que un hijo de una pareja de este mismo sexo puede ser el beneficiario a mitad del seguro de vida, son debates constitucionales de fácil resolución a la luz del derecho constitucional pero que solo se decantaran en la práctica y muchas veces con la suerte de contar con un operador judicial pro-constitucionalización del derecho privado, comercial y de seguros, con lo que la Delegatura de Funciones Jurisdiccionales de la Superintendencia Financiera, pareciera ser el foro más proteccionista para dirimir este tipo de controversias ${ }^{54}$.

53 Sentencia de la Corte Constitucional SU-214 del 2016, referencia: expediente T- 4.167.863 AC, MP: ALBERTO ROJAS RÍOS

54 RESOLUCIÓN NÚMERO 2333 DE 2013 (Diciembre 2013)

"Por la cual se adopta la Ley 1564 de 2012 en los asuntos de competencia de la Superintendencia Financiera en el ejercicio de Funciones Jurisdiccionales. Facultades constitucionales y legales, especialmente las otorgadas por los artículos 116 de la Constitución Política, 326 numeral 8o. del 
En su más reciente fallo, Sentencia T-506/15 55 , pese a no pronunciarse de fondo por no cumplir la tutela con los requisitos legales de inmediatez y daño irreparable, la Corte de nuevo a reiterado la asimilación del compañero permanente con el cónyuge En el asunto bajo examen, se ha planteado una presunta vulneración del derecho a la igualdad del compañero permanente excluido como beneficiario supletivo del tomador de los seguros de personas.

A su turno resulta relevante anotar dentro de los escenarios de constitucionalizarían del derecho mercantil y en especial de la intromisión de la jurisdicción constitucional en los contratos de seguros, damos cuenta de una larga y elaborada lista de pronunciamientos de la alta corporación constitucional, que ha delimitado la libertad contractual dentro de este tipo de contratos.

Dentro de los principales antecedentes ya mencionados, se encuentra la T 1165 de 2001, caso en el que se discutió si resultaba constitucionalmente legítimo a la luz del derecho a la igualdad que una compañía aseguradora se negara a celebrar un contrato de seguro vida con un tomador que padecía el síndrome de inmunodeficiencia adquirida. En la T-1118 2002 ${ }^{56}$, la Sala Tercera de Revisión, evaluó si la decisión negativa de una aseguradora para cotizar el valor de un seguro de accidentes personales a favor de un grupo de discapacitados se oponía al derecho fundamental a la igualdad.

En la T 763 del 2005, le correspondió a la Corte determinar si resultaba constitucionalmente admisible, a la luz a la igualdad, que una entidad bancaria negara a un pastor cristiano la activación de una tarjeta débito aduciendo, para el efecto, que ello no era posible dado que la actividad desempeñada por el solicitante no se encontraba en el marco de las políticas de crédito de tal entidad bancaria. Pero la especial relevancia con que la Corte Constitucional se ha entrometido en las relaciones comerciales

Estatuto Orgánico del Sistema Financiero, 57 de la Ley 1480 de 2011, 24 de la Ley 1564 de 2012 y $4^{\circ}$ numerales 1, 2, 4 y 6 del Decreto 710 de 2012 y, facultades para conocer de las controversias que se susciten entre los consumidores financieros y las entidades vigiladas por este organismo, referidas exclusivamente a la ejecución y el cumplimiento de las obligaciones contractuales que asuman con ocasión de la actividad financiera, bursátil, aseguradora y cualquiera otra relacionada con el manejo, aprovechamiento e inversión de los recursos captados del público". Pertinente rescatar en este asunto la competencia otorgada por el artículo 24 del Código General del Proceso

55 Sentencia de la Corte Constitucional T-506 de 2015, fecha 10 de agosto 2015, Ref expediente T-4.849.334, MP: GLORIA STELLA ORTIZ DELGADO

56 Sentencia de la Corte Constitucional T-1118 del 2002, fecha 9 de diciembre del 2002, Referencia: expediente T-527962, MP: Dr. MANUEL JOSE CEPEDA ESPINOSA 
en relación con las compañías aseguradoras se ven por analogía justificadas en la intromisión que la corte constitucional ha realizado en las relaciones bancarias. En donde a raíz del carácter de actividad de servicio público la vinculación de dichas actividades adquiere un mayor número de conexiones debido a que los servicios cuya prestación le ha autorizado el Estado gozan de una especial trascendencia para los ciudadanos, como puede encontrarse en la sentencia T 697 de $2005^{57}$.

\subsection{Proceso de reclamo del seguro de vida}

A la luz de los artículos 1077 y 1080 del C.Co, el beneficiario o el asegurado tienen la posibilidad de buscar el pago de la indemnización mediante la presentación de una reclamación, la cual debe cumplir dos requisitos: probar el siniestro y probar la cuantía de la pérdida. El asegurado tiene la posibilidad de recurrir a una acción judicial de carácter ejecutivo si se reúnen los requisitos que exige el numeral 3 del artículo 1053 del C. Co, sin embargo es importante precisar a la luz de las palabras del profesor Diaz- Granados (Revista Iberoamericana de seguros, 2008), que habiendo sido objetada la reclamación, para el demandante es altamente riesgoso recurrir a la acción ejecutiva, pues presentada la demanda, junto con la póliza y la carta de objeción, si el juez considera que sí había fundamento en la objeción rechazará el mandamiento ejecutivo. Esta circunstancia supone que la prescripción ha seguido corriendo en contra de la víctima y del asegurado y podría haberse consumado.

El otro camino a la luz de una objeción fundada que obstruiría la vía ejecutiva, sería la acción ordinaria, que corresponde a un proceso declarativo en el cual no hay una obligación previa, clara y exigible.

En el caso en mención la reclamación directa debe ser ejercida directamente contra la aseguradora, sin embargo en la mayoría de casos lo que se presenta es la objeción por parte de la aseguradora, por no encontrarse estipulado en la Ley, la denominación del beneficiario al compañero del mismo sexo, en otras ocasiones como la referida en la sentencia Sentencia T-506/15, expediente T-4.849.334, el régimen

57 Sentencia de la Corte Constitucional T 697 de 2005, fecha 22 de agosto del 2006, Referencia: expediente T-1341929, MP Manuel José Cepeda Espinosa, en donde se determinó que en materia e créditos hipotecarios para la adquisición de vivienda no resulta posible sin violar el derecho al debido proceso, que las entidades bancarias carentes de la autorización de los deudores adelantes la reversión unilateral de las liquidaciones de los créditos cuando el resultado de tales liquidaciones ha beneficiado a los Deudores. 
normativo aplicable, no sólo comprende el Código de Comercio sino también normas especiales, de carácter administrativo, interno de instituciones o incluso colectivo, dependiendo del tipo de seguro de vida si es individual o grupo y si es tomado por una persona en especial y cuyo beneficiarios son especiales de igual manera ${ }^{58}$. Sin embargo esto no impediría de forma alguna que la interpretación en casos de beneficiario supletivo, fuera diferente a la aquí planteada.

En la práctica, las objeciones a este tipo de reclamaciones son comunes y las más de las veces las pruebas que dan conocimiento de la relaciones maritales son tediosas, en especial en los casos en los cuales no existen documentos que den fe de la existencia de la unión marital de hecho ni de la sociedad patrimonial ni tampoco contratos de unión solemne, con lo que son necesarios procedimientos declarativos ${ }^{59}$, lo que complejiza aún más la situación, sin contar con los fenómenos prescriptivos propios del contrato de seguro ${ }^{60}$ (Jaramillo, 2012) y las cuestiones relativas a la interrupción de la prescripción con la presentación de una demanda ${ }^{61}$ máxime si esta demanda no es la propia reclamación

58 El artículo 1191 del C.co indica que se pueden tomar seguros sobre la vida de un tercero, con el consentimiento escrito del asegurado, a su turno el artículo 1064, establece que se podrán tomar seguros sobre un conjunto de personas o intereses debidamente identificados, lo que a la suma posibilita que se tomen seguros colectivos, a favor de terceros con beneficiarios en sus familiares o a quien bien dispongan, de suerte que los organismo públicos o privados a través de organizaciones laborales como fondos de empleados o fondos comunes, puedan tomar seguros para sus asociados en forma colectiva. De igual manera las entidades crediticias toman seguros en nombre de terceros, sus deudores en créditos, para cubrir el riesgo de muerte. Con lo que existen múltiples posibilidades en las calidades de partes del seguro de vida y sus modalidades colectivo, individual, que en la práctica involucran además distintas normativas aplicables.

59 Artículo 22 Código General del Proceso, Competencia de los jueces de familia en primera instancia. 20. De los procesos sobre declaración de existencia de unión marital de hecho y de la sociedad patrimonial entre compañeros permanentes, sin perjuicio de la competencia atribuida a los notarios.

60 (Jaramillo, 2012) La prescripción se desdobla en ordinaria u extraordinaria, la primera se le asigna un término de dos años, contados a partir del momento en que el interesado tuvo conocimiento, real o presunto, del hecho que da causa a la acción y respecto a la segunda consagra un término máximo de cinco años contados a partir del momento en que nace el derecho y en relación con toda clase de personas. La diferenciación entre ambas prescripciones no es teórica sino sustancial, las diferencias recaen en cuanto a:la naturaleza de cada modalidad, las personas contra las cuales corre cada clase de prescripción, el punto de partida para la contabilización, el término a que está sujeto cada prescripción, la improcedencia de la suspensión de la prescripción

61 Concepto 2009049363-001 del 15 de septiembre de 2009 Superfinanciera. SEGUROS, PRESCRIPCIÓN, INTERRUPCIÓN. De otra parte, respecto de la interrupción de la prescripción se advierte que el Código de Comercio no prevé que el aviso del siniestro o la presentación de la reclamación interrumpa la prescripción, motivo por el cual debemos acudir, en virtud de la remisión expresa consignada en el artículo 822 del mencionado código, a las normas generales del derecho civil para efectos de establecer los lineamientos bajo los cuales procedería la interrupción de la prescripción .En este sentido, el artículo 2539 del Código Civil dispone que la prescripción puede interrumpirse natural o civilmente: "Se interrumpe naturalmente por el hecho de reconocer el deudor la obligación, 
sino un proceso conexo necesario para obtener el resultado favorable en el proceso de prescripción, como el proceso ordinario declarativo de unión permanente. Cuestiones que en todo caso, están sujetas a debate y contradicciones entre la doctrina y la jurisprudencia ${ }^{62}$. Cuestiones estas que por sí solas motivan otro estudio en especial.

\section{CONCLUSIONES}

1. Debe de implementarse una regulación de la sobreconstitucionalización que tome en cuenta los efectores nocivos de las sentencias, y que en los casos de enfoque diferencial o interseccionalidad, no solo limite las libertades empresariales por cuenta de los derechos particulares, sino que involucre al Estado en sus decisiones, como garante natural de los derechos de estas poblaciones. De manera que si se resuelve contratar de forma obligatoria un seguro para personas con VIH, entonces se resuelva también crear un fondo de subsidio de primas, como el que existe con el seguro agrario.

2. A partir de las distintas concepciones de constitucionalismo, este irradia al ordenamiento, pero también llena vacíos, suple necesidades, actúa como configurador legislativo.

3. La sobreconstitucionalización del derecho de seguros, se ha dado por cuenta de pronunciamientos jurisprudenciales, que limitan libertades individuales, derechos y crean obligaciones, en especial en relaciones con sujetos de especial protección constitucional. . Se evidencia que existen posibilidades para nuevas constitucionalizaciones, y el ejemplo del compañero permanente o conyugue del mismo del sexo en el seguro de vida, es un buen ejemplo para entender el racionamiento constitucional y el fundamento normativo, que lleva a la constitucionalización.

ya expresa, ya tácitamente”. Por su parte, el artículo 90 del Código de Procedimiento Civil y (94 DEL CODIGO GENERAL DEL PROCESO) señala el momento en que opera esta última al disponer que la prescripción se interrumpe civilmente en la fecha de presentación de la demanda únicamente cuando su notificación se surte dentro del término previsto legalmente, en caso contrario, se interrumpe con la notificación de la demanda.

62 La Corte Suprema de Justicia en el (2011) - Expediente No. 00551, MP: CARLOS IGNACION JARAMILLO, se pronunció sobre la interrupción de la prescripción del contrato de seguro en los siguientes términos, contradiciendo la concepción doctrinaria general de la interrupción "Ciertamente que, desde esa perspectiva, la extinción de las acciones derivadas del contrato de seguro por medio de la prescripción se halla regulada integramente en el Código de Comercio, lo que imposibilita sobreponer a las disposiciones de éste las reglas que, como las de suspensión de los términos de prescripción, consagra el Código Civil." 


\subsection{Conclusiones frente al caso especial del seguro de vida para beneficiarios del mismo sexo}

1. Frente al seguro de vida y su móvil determinante de indemnización del daño a los causahabientes, pese al principio de mera liberalidad, que responde a la naturaleza comercial del seguro, como producto, pero no a su vocación jurídica:

2. La concepción actual del seguro de vida, es aquella mediante la cual el suscriptor del seguro tiene como móvil determinante del contrato, la indemnización del daño eventual que con su muerte ha de menoscabar su patrimonio el seguro de vida tiene un móvil determinante circundante con el principio de la indemnización y llegan a evaluar en cabeza de quién se radica el daño y qué patrimonio se beneficia con derecho a la indemnización. El daño radica, con el derecho a la indemnización, en cabeza de los causahabientes. El patrimonio completo, incluidos la vida y la capacidad de trabajo y de renta, no tienen por qué sufrir quebranto con la muerte y, por lo tanto, deben pasar intacto a los herederos, ello dado que el seguro es precisamente el sustitutivo económico de bienes.

3. Pese a que el beneficiario natural del seguro de vida, son los causahabientes por ser quienes soportan de manera directa el daño y quienes se encuentran entonces legitimados para recibir un resarcimiento indemnizatorio, en realidad la libertad de estipulación contenida en el artículo 1141 del C.Co, con la que la mera liberalidad del tomador es la Ley para las partes, surge como característica definitoria de la identificación del beneficiario en el contrato de seguro vida individual. De suerte que la máxima doctrinaria de quien es el beneficiario natural, queda relegada a una norma supletiva de voluntad contenida en el artículo 1142 del C.co, que cubre el defecto o ineficacia de la designación hecha en ejercicio de la liberalidad del asegurado cuando no se hace uso de esta libertad y en defecto no se estipula a nadie como beneficiario, ello a partir del sentido de los artículos 1142, 1137 del C.co y 411 del C.C, este último que coloca como fundamento del interés asegurable y la designación supletiva, la obligación de brindar alimentos.

4. En conclusión en los casos en que no ha existido designación expresa del beneficiario, la designación se hará a título legal de acuerdo con las reglas de los artículos 1137, 1142 del Código de Comercio 
y las del artículo 411 del Código Civil. La designación del beneficiario a titulo legal se dará a favor del cónyuge y herederos en igual porción (1142 C.Co), (que abarca también al compañero o compañera permanente Sentencia C-844 del 28 de octubre de 2010) , en el entendido de que el objeto del contrato de seguro de vida, es decir el interés asegurable, recae en un tercero asegurado o beneficiario que es el titular de la prestación asegurada(sin importar si ha sido designado o no), una vez ocurrido el siniestro de muerte, pues en el riesgo de muerte, sería absurdo pensar en una prestación para el difunto. Dado que, cuando el beneficiario es a título legal, su legitimidad en reclamar la prestación se da a la luz de existir un fundamento razonable basado en las relaciones entre las partes, de consanguineidad o de afinidad siendo cónyuges o herederos (1137 C.Co).

5. Acerca de la obligación que tiene los operadores judiciales de interpretar desde un punto de vista constitucional la normas y su aplicación en casos concretos:

6. Los operadores judiciales que conozcan de demandas de reclamación de indemnización, en contra de compañías aseguradoras, por parte de beneficiarios supletivos, de una unión permanente del mismo sexo o como suscriptores del contrato de unión solemne, tendrían que abocar por un proceso de argumentación constitucional, pero más importante que ello una interpretación constitucional que incidan en determinar el alcance de las normas comerciales.

7. Sobre el proceso de reclamación judicial del seguro de vida por parte del compañero permanente del mismo sexo y los problemas jurídicos que representa:

8. En la práctica, las objeciones a este tipo de reclamaciones son comunes y las más de las veces las pruebas que dan conocimiento de la relaciones maritales son tediosas, en especial en los casos en los cuales no existen documentos que den fe de la existencia de la unión marital de hecho ni de la sociedad patrimonial ni tampoco contratos de unión solemne, con lo que son necesarios procedimientos declarativos $^{63}$, lo que complejiza aún más la situación, sin contar con los

63 Artículo 22 Código General del Proceso, Competencia de los jueces de familia en primera instancia. 20. De los procesos sobre declaración de existencia de unión marital de hecho y de la sociedad patrimonial entre compañeros permanentes, sin perjuicio de la competencia atribuida a los notarios. 
fenómenos prescriptivos propios del contrato de seguro ${ }^{64}$ (Jarami1lo, 2012) y las cuestiones relativas a la interrupción de la prescripción con la presentación de una demanda ${ }^{65}$ máxime si esta demanda no es la propia reclamación sino un proceso conexo necesario para obtener el resultado favorable en el proceso de prescripción, como el proceso ordinario declarativo de unión permanente. Cuestiones que en todo caso, están sujetas a debate y contradicciones entre la doctrina y la jurisprudencia ${ }^{66}$. Cuestiones estas que por sí solas motivan otro estudio en especial.

\section{BIBLIOGRAFÍA}

Acero Gallego, Luis Guillermo, Teoría aplicada de la jurisdicción 2004 Universidad Externado de Colombia

Arrieta Flórez. La constitucionalización del Derecho y su incidencia en Colombia. Vicente de Jesús Arrieta Flórez Vol. 2, núm. 2 (2009) http://www.coruniamericana.edu.co/publicaciones/ojs/index.php/pensamientoamericano/article/ view/23

64 (Jaramillo, 2012) La prescripción se desdobla en ordinaria u extraordinaria, la primera se le asigna un término de dos años, contados a partir del momento en que el interesado tuvo conocimiento, real o presunto, del hecho que da causa a la acción y respecto a la segunda consagra un término máximo de cinco años contados a partir del momento en que nace el derecho y en relación con toda clase de personas. La diferenciación entre ambas prescripciones no es teórica sino sustancial, las diferencias recaen en cuanto a:la naturaleza de cada modalidad, las personas contra las cuales corre cada clase de prescripción, el punto de partida para la contabilización, el término a que está sujeto cada prescripción, la improcedencia de la suspensión de la prescripción

65 Concepto 2009049363-001 del 15 de septiembre de 2009 Superfinanciera. SEGUROS, PRESCRIPCIÓN, INTERRUPCIÓN. De otra parte, respecto de la interrupción de la prescripción se advierte que el Código de Comercio no prevé que el aviso del siniestro o la presentación de la reclamación interrumpa la prescripción, motivo por el cual debemos acudir, en virtud de la remisión expresa consignada en el artículo 822 del mencionado código, a las normas generales del derecho civil para efectos de establecer los lineamientos bajo los cuales procedería la interrupción de la prescripción. En este sentido, el artículo 2539 del Código Civil dispone que la prescripción puede interrumpirse natural o civilmente: "Se interrumpe naturalmente por el hecho de reconocer el deudor la obligación, ya expresa, ya tácitamente”. Por su parte, el artículo 90 del Código de Procedimiento Civil y (94 DEL CODIGO GENERAL DEL PROCESO) señala el momento en que opera esta última al disponer que la prescripción se interrumpe civilmente en la fecha de presentación de la demanda únicamente cuando su notificación se surte dentro del término previsto legalmente, en caso contrario, se interrumpe con la notificación de la demanda.

66 La Corte Suprema de Justicia en el (2011) - Expediente No. 00551 se pronunció sobre la interrupción de la prescripción del contrato de seguro en los siguientes términos, contradiciendo la concepción doctrinaria general de la interrupción "Ciertamente que, desde esa perspectiva, la extinción de las acciones derivadas del contrato de seguro por medio de la prescripción se halla regulada integramente en el Código de Comercio, lo que imposibilita sobreponer a las disposiciones de éste las reglas que, como las de suspensión de los términos de prescripción, consagra el Código Civil." 
Doing Business. Doing Business 2016, (Revisada el 29 de Agosto del 2016, disponible en http://www.doingbusiness.org/ /media/GIAWB/Doing\%20Business/ Documents/Annual-Reports/English/DB16-Full-Report.pdf)

Calderón Villegas, Juan Jacobo. La constitucionalizarían del derecho comercial: algunas de las huellas trazadas por la jurisprudencia de la Corte Constitucional en Colombia, Universidad del Rosario, 2008.

BaChiller NuÑEz, Julio, Seguro de caución: doctrina, legislación, jurisprudencia / Julio Bachiller Nuñez[...et. al.] Buenos Aires : Abeledo-Perrot, 1995. Spa 188p.

Bidart Campos, Germán J. Manual de la Constitución Reformada Tomo I Editorial: Ediar Formato: doc, 2014

Cabra Gerardo Monroy, Introducción Al Derecho Duodécima Edición Marco Editorial Temis, 2009

Castro, Gullermo. La consolidación discursiva en el derecho. La constitucionalización como fenómeno histórico 2009. Libros y Revistas Revista de Derecho PrivadoNúm. 48, Diciembre 2012 La consolidación discursiva en el derecho, disponible en http://doctrina.vlex.com.co/vid/discursiva-derecho-513939134, última fecha de revisión 18 agosto 2016

Diaz-Granados Juan Manuel, Revista Iberoamericana de Seguros, Pontificia Universidad Javeriana, 2008. Artículo las acciones relacionadas con el seguro de responsabilidad civil.

Kelsen, Hans, Teoría pura do Direito, Comimbra, Aremnio Amado, 1979, pag 269

Konrad - Adenauer - Stiftung, Anuario de derecho constitucional latinoamericano, Edición 2004

Ferreyra Raúl Gustavo, Fundamentos constitucionale, Editorial Ediar, Buenos Aires, 2015

Friedrich C. von Savigny, Sistema de derecho privado romano, trad. De J. Mesía y Manuel Poley, Madrid, 1879, pág 63.

JARAmillo CARlos Ignacio, La prescripción en el Contrato de seguro, 2012, Universidad Externado de Colombia

López Blanco Hernán Fabio Instituciones de Derecho Procesal Civil Colombiano, Dupré, 2002 - 2004

López Blanco Hernán Fabio "Comentarios al Contrato de Seguros”, 2009, Universidad Externado

López Cuellar Nelcy, Rincon Cárdenas Erick y Calderon Juan Jacobo "La constitucionalización del derecho privado en Colombia: supuestos de investigación”Universidad del Rosario, 2014. 
Moreno Urán Carlos Andrés, Esponda Katherine, 2008, El concepto de autonomía en la fundamentación de la metafísica de las costumbres de Kant. Departamento de Filosofía Universidad del Valle Cali, Colombia, disponible en http:// www.javeriana.edu.co/cuadrantephi/pdfs/N.17/4.\%20Kant.pdf, última entrada 16 agosto 2016.

Mendoza Vargas Janne \& Echeverri García Claudia, El seguro de cumplimiento y la contratación pública, LEYER, 2008

Ossa Efren, Teoría General de seguros: el contrato, 1985

Planiol Marcel et Ripert Georges, Traité practique de Droit Civil Francais, VI, Obligations, LGDJ, Paris, 1930.

Rodríguez Peñaranda María Luisa, Heber Joel Campos Bernal, 2013. , Imperialismo Constitucional. UNIJUS.

Rojas Gómez Miguel Enrique, La reforma al Código de Procedimiento Civil 2003, Universidad Externado de Colombia.

Quinche Manuel Fernando, Derecho constitucional Colombiano, TEMIS, 2015, Bogotá, Colombia

QuiJAno JAIRo PARRA, Los terceros en el proceso civil: llamamiento en garantía en la jurisdicción contencioso-administrativa, 2001, Librería Ediciones del Profesional Ltda, $6^{\circ}$ ed.

Urna de Cristal, 2016. Acuerdos de la Habana. (Recuperado el día 29 de Agosto del 2016, disponible en http://www.urnadecristal.gov.co/sites/default/files/ acuerdo-final-habana.pdf)

\section{Sentencias y normas}

Corte Suprema de Justicia (2004). Declaración pública Corte Suprema de Justicia de fecha 3 de marzo del 2004. (En línea. (Recuperado el día 18 Julio del 2016, disponible en http:// www.ramajudicial.gov.co/csj_portal/assets/Revista\%20 No.\%2018.pdf).

Autos de la Corte Constitucional $N^{\circ} 251$ protección de Niños, niñas y adolescentes del 2008; 004 protección a indígenas, 005 protección Afrodescendientes, 006 protección discapacidad y 092 protección mujeres víctimas, todos estos del 2009.

Corte Constitucional, Sentencia C-228/10, fecha 28 de abril 2010, MP: Luis Ernesto Vargas Silva M. P.

Corte Constitucional, Sentencia C-263/11, abril 6 del 2011, RAD: D-8270, Jorge Ignacio Pretelt Chaljub, M.P. 
Corte Constitucional, Sentencia C-197/12, 14 de marzo 2012, RAD: D-8533, Jorge Ignacio Pretelt Chaljub M.P

Código General del Proceso Ley 1564 2012. Estatuto Orgánico del Sistema Financiero Decreto 663 de 1993

Código de Procedimiento Administrativo y de lo Contencioso Administrativo CPACA, Ley 1473 del 2011

José Luis Benavides, 2015, Comentarios al Código Contencioso Administrativo y de lo Contencioso Administrativo, Universidad Externado de Colombia,

Tribunal Constitucional Federal, Sentecia Luth Sentencia BVerfGE 7, 198, Sentencia de la Primera Sala, del 15 de enero, 1958.

Ley Fundamental de Bonn en 1949

Corte Constitucional, T-240 de 1993, JUNIO 23 DE 1993, REF: Expediente T-9665 Magistrado Ponente: Dr. Eduardo Cifuentes Muñoz

Corte Constitucional T-222 8 de marzo del 2004, Referencia: expediente T-740383, Magistrado Ponente: Dr. Eduardo Montealegre Lynett.

Corte Constitucional, Sentencia T- 1042 de 2001, Septiembre 28 de 2001, Referencia: expediente T-464818, M.P Manuel José Cepeda E.

Corte Constitucional T 982-2001, el 13 de Septiembre de 2001, Referencia: expediente T-459129, Dr. Manuel José Cepeda Espinosa M.P

Corte Constitucional, Sentencia T-1180-2002, Fecha 2 de diciembre de 2002, Referencia: expediente T-1.997.283, MP: Dr. Humberto Antonio Sierra Porto.

Corte Constitucional T 1165 de 2001, fecha 6 de noviembre del 2001, Referencia: expediente T-500.674, MP Dr. Alfredo Beltrán Sierra,

Sentencia de la Corte Constitucional T-1118 del 2002, fecha 9 de diciembre del 2002, Referencia: expediente T-527962, MP: Dr. Manuel José Cepeda Espinosa

Corte Constitucional T 763 del 2005, fecha 9 de diciembre del 2002, Referencia: expediente T-527962, Magistrado Ponente: Dr. Manuel Jose Cepeda Espinosa,

Corte Constitucional T-517 del 2006, fecha 7 de diciembre del 2006, Referencia: T-1308125, Magistrado Ponente: Dr. Marco Gerardo Monroy Cabra

Corte Constitucional T-416 de 2007, fecha 24 de mayo del 2007, Referencia: expediente T-1534164, Magistrado Ponente: Dr. Alvaro Tafur Galvis

Corte Constitucional, T-433de 1992, fecha 24 junio 1992, Magistrado ponente Dr. Simon Rodríguez Rodríguez. 
Corte Constitucional SU-157 de 1999, fecha 10 de marzo de 1999,r eferencia: Expedientes T-153.327 y T-152.413 (acumulados), Magistrado Ponente: Dr. Alejandro Martínez Caballero

Corte Constitucional, SU-167 de 1999, fecha 17 de marzo de 1999, Referencia: Expediente T-176.083, Magistrado Ponente: Dr. Alejandro Martínez Caballero

Corte Constitucional C-432 de 2010, fecha 2 junio 2010, Referencia: expediente D-7946, Magistrado Ponente: Dr. Humberto Antonio Sierra Porto.

Corte Constitucional T-435 de 1997, Referencia: Expediente T-130126, Magistrado Ponente: Dr. Eduardo Cifuentes Muñoz.

J.M Piniés- R. Tornil, aRIEL 1973, Manual práctico del seguro sobre la vida, ParisFrancia

Corte Suprema de Justicia, Ref: exp. 05001-3103-001-2006-00038-01, fecha 25 de mayo 2012, Magistrada Ponente RUTH MARINA DÍAZ RUEDA.

Corte Suprema de Justicia, Ref.exp Expediente 0500131030021999 00359, fecha 06 Julio de 2007, MP: CARLOS IGNACIO JARAMILLO JARAMILLO

Corte Constitucional Sentencia C-844 del 28 de octubre de 2010, Sala Plena. M.P. María Victoria Calle Correa.. Expediente D-8130. Spa. LEY 54 DE 1990 (diciembre 28) modificada por la Ley 979 de 2005, fue declarada EXEQUIBLE por la Corte Constitucional, mediante Sentencia $\underline{\text { C-075 }}$ de 2007, en el entendido que el régimen de protección en ella contenido se aplica también a las parejas homosexuales. por la cual se definen las uniones maritales de hecho y régimen patrimonial entre compañeros permanentes.

Corte Constitucional Sentencia T-506/15, expediente T-4.849.334, fecha 10 de agosto del 2015, MP: GLORIA STELLA ORTIZ DELGADO

Corte Constitucional en Sentencia C-844 del 28 de octubre de 2010Sala Plena, M.P. María Victoria Calle Correa. Expediente D-8130

Corte Constitucional como Sentencia T.582 del 27 de julio de 2010, Expediente T-2601994. Sala Quinta de Revisión. M. P. Jorge Iván Palacio Palacio

Corte Constitucional C-410 de 1996, fecha 4 de Septiembre de 1996, Referencia: Expedientes D-1203, D-1204, D-1205, D-1206, D-1212, D-1213, D-1214 y D-1218 (acumulados), Magistrado Ponente:Dr. HERNANDO HERRERA VERGARA

Corte Constitucional C-1126 de 2004, fecha 9 de Noviembre de 2004, Ref. Expe D-5259, M.P. Manuel José Cepeda Espinosa.

Corte Constitucional T-494 de 1992, Ref: EXPEDIENTE 1909, M.P. Ciro Angarita Barón. 
Corte Constitucional Sentencia C-014 de 1998, fecha 4 de febrero 1998, Referencia: Expedientes D1735 y D-1740, acumulados, Magistrado Ponente: Dr. Eduardo Cifuentes Muñoz.

Corte Constitucional C-098 de 1996, 7 de Marzo de 1996, Ref.: Demanda No D-911, Magistrado Ponente: Dr. Eduardo Cifuentes Muñoz

Corte Constitucional C-985 del 2005, fecha 26 de septiembre de 2005, Referencia: expediente D-5737, MP: Dr. Alfredo Beltrán Sierra

Corte Constitucional C-238 de 2012, fecha, Referencia expediente D-8662, Mp: Gabriel Eduardo Mendoza Martelo

Corte Constitucional C-075 del 2007, fecha 7 de febrero 2007, referencia expediente D-6362, MP: Dr. Rodrigo Escobar Gil

Corte Constitucional C-577 del 2011, fecha 12 de enero del 2011, referencia Expedientes acumulados D-8367 y D-8376, Mp: Gabriel Eduardo Mendoza Martelo

Sentencia de la Corte Constitucional SU-214 del 2016, referencia: expediente T4.167.863 AC, Mp: Alberto Rojas Ríos

RESOLUCIÓN NÚMERO 2333 DE 2013 (Diciembre 2013)

Corte Constitucional T-506 de 2015, fecha 10 de agosto 2015, Ref expediente T-4.849.334, Mp: Gloria Stella Ortiz Delgado

Corte Constitucional T 697 de 2005, fecha 22 de agosto del 2006, Referencia: expediente T-1341929, MP Manuel José Cepeda Espinosa,

Concepto 2009049363-001 del 15 de septiembre de 2009 Superfinanciera. SEGUROS, PRESCRIPCIÓN, INTERRUPCIÓN.

Corte Suprema de Justicia en el (2011) - Expediente No. 00551, Mp: Carlos Ignacion Jaramillo 
